\title{
Las prácticas sanitarias en tiempos de epidemia en la Sevilla del siglo XVII según los enfermeros Obregones
}

\author{
Health practices in times of epidemic in the Seville of the \\ seventeenth century according to the Obregones nurses
}

\author{
Antonio Claret García Martínez \\ Profesor Titular de la Universidad de Huelva \\ https://orcid.org/0000-0002-4631-895X
}

\begin{abstract}
Resumen: En 1635 fundan los enfermeros Obregones en Sevilla el Hospital de Convalecientes de Ntra. Sra. del Buen Suceso y desarrollaron una ingente actividad asistencial, que se hizo especialmente difícil con las sucesivas epidemias que sufrió la ciudad. Con estos enfermeros llegó a Andalucía una forma de entender la Enfermería que poseía ya a comienzos del siglo XVII un reconocimiento social muy importante. Dentro de su ideal de vida como enfermeros, los hermanos Obregones incluyeron la asistencia a los pobres enfermos hasta en las condiciones más difíciles y dramáticas, como eran las epidemias que asolaron a toda Andalucía entre los siglos XVI y XVII y lo hicieron con los conocimientos, cuidados enfermeros, terapéutica y remedios existentes en la época.
\end{abstract}

Palabras clave: Bernardino de Obregón, Enfermería, peste, enfermeros Obregones, prácticas sanitarias, Sevilla.
Abstract: In 1635 the Obregones nurses founded the Hospital de Convalecientes de Ntra. Sra. del Buen Suceso in Seville and developed a huge healthcare activity, which became especially difficult with the successive epidemics that the city suffered. With these nurses, a way of understanding Nursing arrived in Andalusia, which already had a very important social recognition at the beginning of the 17th century. Within their ideal of life as nurses, the Obregones brothers included assisting the sick poor even in the most difficult and dramatic conditions, such as the epidemics that ravaged all of Andalusia between the 16th and 17th centuries and they did so with knowledge, nursing cares, therapeutic and existing remedies at the time.

Keywords: Bernardino de Obregón, Nursing, plague, Obregon nurses, sanitary practices, Seville. 


\section{PRIMERA PARTE \\ BERNARDINO DE OBREGÓN (1540-1599). UN ENFERMERO REFORMADOR}

\section{INTRODUCCIÓN. TIEMPOS DE EPIDEMIA PRESENTES Y PASADOS}

Estamos viviendo una situación inimaginable hace poco más de un año, que los países "desarrollados y ricos" sufrieran una enfermedad epidémica a nivel global era una situación que considerábamos del pasado, de los libros de historia. Pensábamos que el desarrollo tecnológico, el avance de la ciencia y las actuales condiciones de vida habían hecho cambiar el curso de la existencia humana. ¡Pero esto no es del todo así!

Todo ello nos está haciendo mirar hacia atrás, a comparar situaciones, a conocer y comprender algo mejor el dolor, los logros que las sociedades han ido consiguiendo con el paso de las generaciones y a replantear valores y sentimientos. ¡Mirar hacia fuera, sí, pero siempre mirando hacia adentro!

El tema central de estas Jornadas está dedicado a las epidemias en la historia. Con una mirada actual, intentaremos conocer cómo las gentes de los siglos XVI y XVII se enfrentaron a situaciones de enfermedad y carencias extremas y cómo fueron superándolas, a pesar de la tragedia que vivieron, perdiendo a sus seres queridos y reconstruyendo sus vidas. El paso del tiempo malcuró las heridas que permanecieron indelebles en sus recuerdos y fueron pasando de generación en generación. Hoy, mejor que nunca, los recordamos.

\section{BERNARDINO DE OBREGÓN, FUNDADOR DE LA CONGREGACIÓN DE LOS HERMANOS ENFERMEROS POBRES}

El 6 de agosto de 1599 fallecía en el Hospital General de Madrid Bernardino de Obregón (1540-1599), cuando asistía a enfermos contagiados de peste. Aunque había sido habilitado un hospital en las afueras de la ciudad para acoger a los enfermos contagiados, algunos de ellos fueron ingresados en otros hospitales, en los que también se propagó el contagio: 
"Quando volvió de Valençia [Bernardino] había pestilençia en Madrid; híçose un hospital para reçibir y curar a todos los apestados. Trayan algunas veçes algunos al Hospital General y haçíasele muy de mal que se los rebajasen, porque quisiera él ejerçitar su caridad en cosa tan peligrosa y trabaxosa $(. . .)^{\prime \prime 1}$.

No rehuyó Bernardino asistir a los enfermos con dolencias tan peligrosas, aunque intentando guardar las medidas que en la época se consideraban más adecuadas para atajar el mal e impedir su desarrollo. Sin embargo, Bernardino cayó también

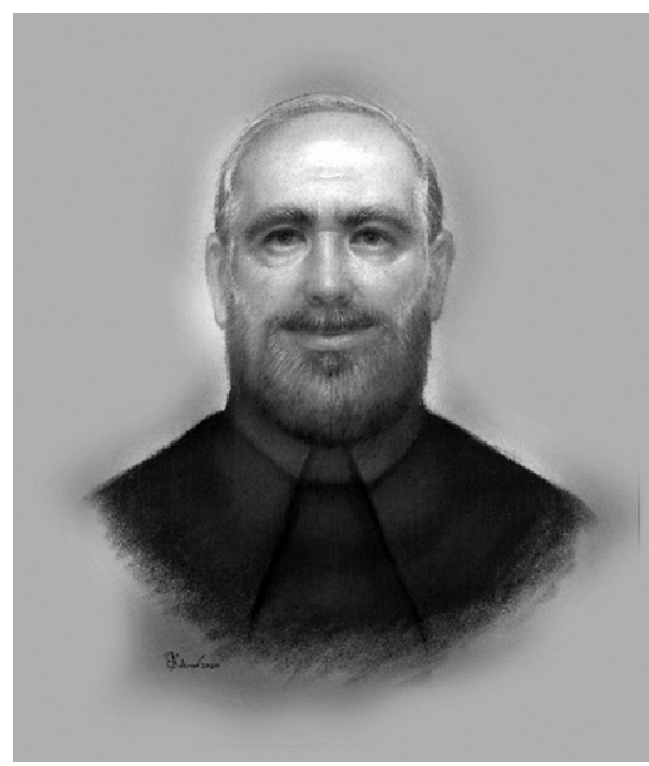

Ilustración 1.

E. Kabirov: Bernardino de Obregón (Burgos, 1540-Madrid, 1599).

Reformador de la Enfermería española.

Fondo: Archivo y Biblioteca Qalat Chábir A.C. Alcalá de Guadaíra. contagiado, después de enfermar otros tres hermanos antes que él por cuidar a un enfermo ingresado en el Hospital General:

"Pegósele luego la seca a este enfermero de aquello poco que la tocó y trató. Quando el Hermano vio que su enfermero estaba herido, púsole en un aposento aparte y señaló otro enfermero que le curase. Muere el primero y pégasele el mal al segundo y entra otro enfermero a curarle y muere el segundo. Pone otro enfermero y muere el terçero; todos a tres o quatro días que no duraban; más el Hermano había sentido las muertes de sus Hermanos porque eran muy grandes sujetos.

1 Archivo Diocesano de Toledo. Manuscrito con La vida del Hermano Bernardino de Obregón, Sieruo de los Pobres, Padre y fundador de los Hermanos enfermeros que los siruen en el Hospital General de Madrid y de su Congregaçión, escrita por el liçençiado Pedro de Bárçena, Comissario de la Sancta Inquisición y Arcipreste de Rauanera de Soria. En Información de la uida y costumbres del Venerable Hermano Bernardino de Obregón. Anduuo en ella el Hermano Pedro Lagarto de Cepeda, natural de Toledo. Año1633, con signatura 3.466, Primera Pieza, ff. 37v-38r. 
Los demás Hermanos tuvieron muy grande miedo de ver lo que había pasado. Métese el sancto varón a curar al postrer Hermano y luego se le pegó la seca y della murió con grandíssimos dolores (tan grandes como los de urina), pero con grandíssima paçiençia dada del çielo, alabando y glorificando a Dios, dándole graçias por las misericordias qual había hecho y exortando a sus Hermanos a la caridad con los pobres y cumplimiento de su instituto" 2 .

Su muerte fue reflejo de su vida, cuando lo abandonó todo siendo joven y decidió dedicarse al cuidado de los enfermos.

Bernardino de Obregón formaba parte en su juventud del círculo cercano del rey Felipe II y con 27 años de edad, en 1567, sufrió una profunda crisis emocional que le llevó a dejar la Corte, a frecuentar los hospitales de Madrid y a dedicarse al cuidado de los enfermos y marginados de la sociedad de su época. Fundó una congregación de enfermeros que se expandió por toda España y Portugal y por algunas ciudades de Europa y América y se convirtió en uno de los grandes reformadores de la Enfermería en España. Él decidió“hacerse enfermero"y lo fue el resto de su vida.

Hombre de gran formación, con su trabajo en los hospitales de Madrid, Bernardino pudo comprobar personalmente las carencias en las prácticas asistenciales de su época y puso en marcha un ambicioso proyecto reformador que incluía la mejora de la formación de los enfermeros y la fundación de centros hospitalarios. Para ello, contó durante toda su vida con el apoyo del propio Monarca, Felipe II. En 1568 comenzó a dar forma a su congregación de enfermeros, que serían conocidos popularmente como "enfermeros obregones", que pervivieron en España hasta finales del siglo XIX.

En las reglas que él mismo compuso para su Congregación hacía referencia expresa a su preocupación por la "asistencia a los enfermos contagiados de peste". Así, en el Capítulo III (primera edición de las Constituciones y Regla, impresas en el año 1634), se recoge que los hermanos enfermeros debían asistir, incluso, a los enfermos contagiados de peste, como puede observarse en las preguntas que se les formulaban a los jóvenes que deseaban entrar en la Congregación:

2 Archivo Diocesano de Toledo. Manuscrito con La vida..., ff. 37v-38r. 
"Capítulo III. De los que deben ser admitidos al hábito de novicio y el modo con que se han de admitir.

Pregunta 5. Ya habéis visto, hermano, poco más o menos, lo que los hermanos tenemos por exercicio y obligación, que es curar o servir a los pobres enfermos de día y de noche de todas enfermedades de qualquier calidad y condición que sean, aunque sea peste, ¿atrevéis os a ellos?"3.

Bernadino de Obregón había conocido a lo largo de su vida epidemias altamente contagiosas en Madrid o las había oído propagarse en otras partes del Reino, conocía muy bien sus devastadores efectos y los temores que su contagio causaban en las gentes. Por ello, hizo alusión expresa a las epidemias en las reglas o constituciones que elaboró para los hermanos de su Congregación, porque sabía que, antes o después, tendrían que vivir personalmente estas experiencias, como así ocurrió a finales del siglo XVI y a todo lo largo del siglo XVII en los distintos brotes epidémicos que padeció la Península Ibérica.

Esta preocupación de Bernardino por los enfermos contagiados de peste perduró en el tiempo y se transmitió en los siglos siguientes a sus hermanos de congregación, siendo una característica del Enfermero Obregón que resaltaron biógrafos posteriores, como se recoge en la biografía escrita por Luis Bernardino de Obregón e impresa en 1724:

"Assí, Bernardino dexó a los suyos por especial precepto que en habiendo pestes, sean ellos los primeros que se consagren; si Armadas, los únicos que las visiten; si Cárceles en los lugares donde moran, los primeros que las assistan, viendo y registrando si tienen enfermos, porque los que en ellas están, están por enormes delictos, éstos horrorizan a los más piadosos y son causa de sus mayores desamparos, y assí los mandó cuidassen de ellos como si estuviessen en sus Hospitales y, aunque fuesse con suma descomodidad, no los dexassen de assistir y curar" ${ }^{\prime \prime}$.

3 Constituciones y regla de la Mínima Congregación de los Hermanos Enfermeros Pobres, Dispuestas y ordenadas por Ntro. Padre y fundador el Venerable Bernardino de Obregón, escritas de su mano y manda sus hijos las observen y Guarden. En Madrid por Francisco De Ocampo. Año de 1634. Tratado Segundo:"De los que pueden admitir y deuen ser admitidos, y del modo de admitirlos en nuestra Congregación. Cap. III. “De los que deuen ser admitidos al hábito de nouicio, y el modo con que se han de admitir", f. 18r.

4 L. Bernardino de Obregón, Vida y Virtudes del Siervo de Dios Bernardino de Obregón. Madrid, 1724, f. 112. 


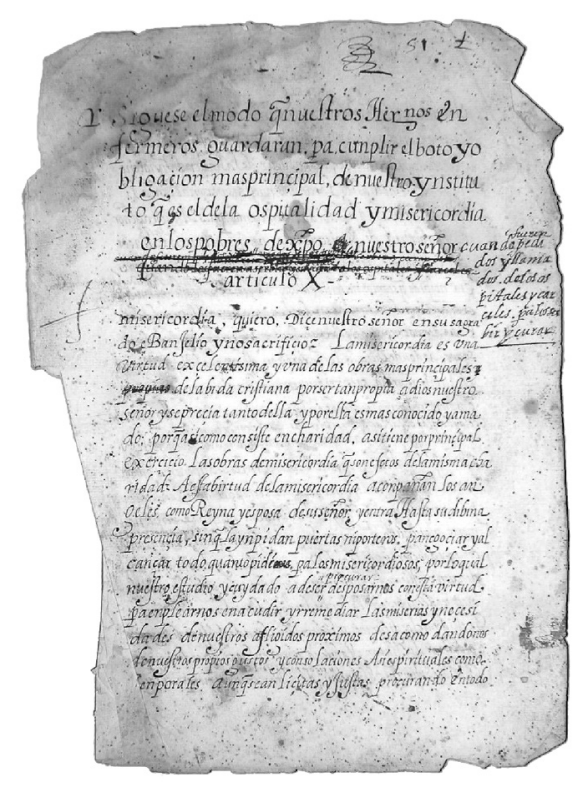

Ilustración 2.

Capítulo X de las Reglas manuscritas corregidas por el propio Bernardino de Obregón. Libro de Beatificación de Bernardino de Obregón. Archivo Diocesano de Toledo. En Información de la uida y costumbres del Venerable Hermano Bernardino de Obregón. Anduuo en ella el Hermano Pedro Lagarto de Cepeda, natural de Toledo. Año1633, con signatura 3.466, Primera Pieza, f. 50r.
Quizás fueran las circunstancias del destino las que hicieron que finalmente el propio Bernardino muriera en una epidemia de peste, aquella que tanta preocupación le había causado durante toda su vida y de la que encomendó encarecidamente se ocuparan sus hermanos.

Durante los más de 30 años que ejerció como enfermero hasta su muerte, y resultado de sus lecturas, el trato con médicos, cirujanos y boticarios y de la investigación personal, Bernardino fue reuniendo un corpus de conocimientos que compartió con sus hermanos a lo largo de los años, dejándoles el encargo expreso de que con todos estos conocimientos elaboraran e imprimieran un tratado para la formación de los enfermeros, que finalmente vería la luz por primera vez algunos años después, en $1617^{5}$. También consideramos como una obra fundamental para conocer el pensamiento y los conocimientos enfermeros de Bernardino de Obregón las reglas que compuso en torno a 1592 durante su estancia en Lisboa y Évora. Estas dos obras, además de algunas biografías, son la base para conocer y comprender la importante labor reformadora de la enfermería que llevó a cabo.

5 De este tratado se hicieron otras 5 ediciones más, una de ellas en lengua portuguesa. 

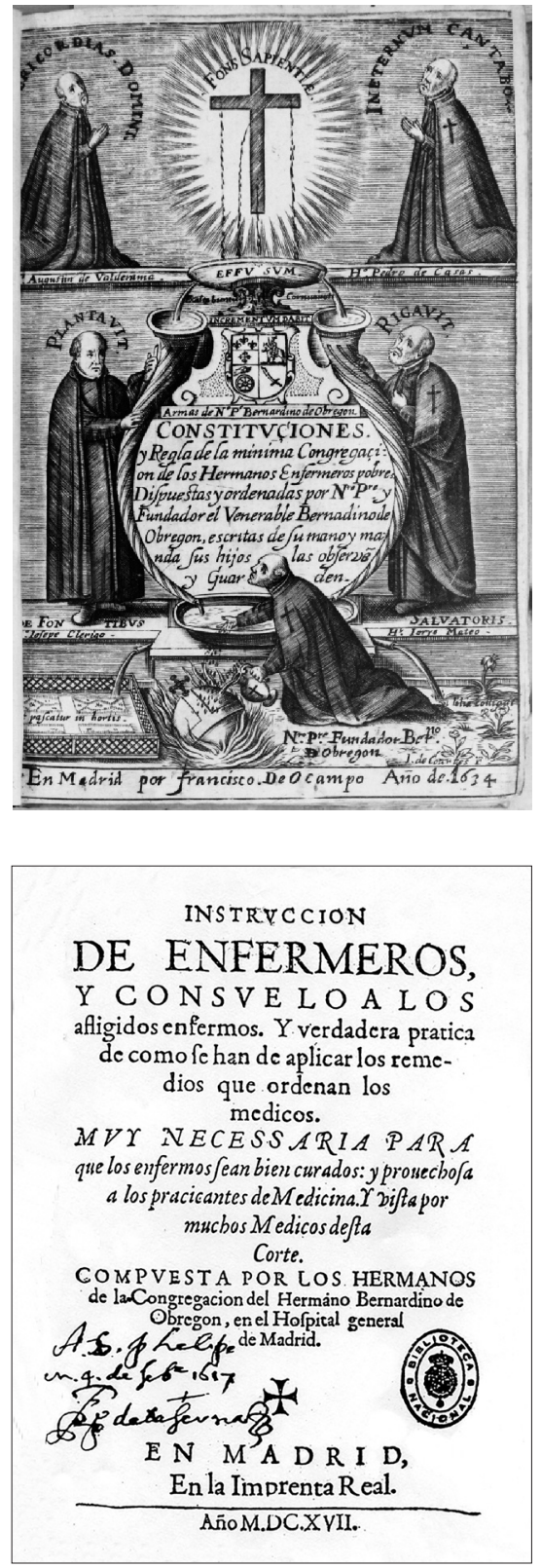

Ilustración 4.

Portada de la primera edición de Instrucción de Enfermeros. Madrid, 1617. (Biblioteca Nacional. Madrid).
Ilustración 3.

Portada de las Constituciones y Regla de la Minima Congregación de los Hermanos Enfermeros Pobres, primera edición. Madrid, 1634.

Fondo: Archivo y Biblioteca Qalat Chábir A.C. Alcalá de Guadaíra.

TRATADO

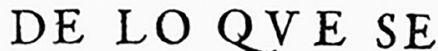
HA DE HAZER CON los que eftan en el articulo de la muerte, facado de duerfos libros efpirituales.

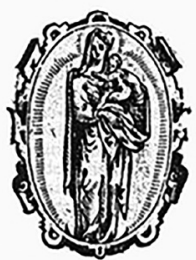

CON PRIVILEGIO.

En Madrid, En la Imprenta Real.

A60 M.DC.XXY.

\section{Ilustración 5.}

Portada de Tratado de lo que se ha de hazer con los que están en el artículo de la muerte. Madrid, 1625. La obra fue compuesta por los enfermeros

Obregones con el objetivo de prestar cuidados especializados al enfermo moribundo.

(Biblioteca Universitaria de Sevilla). 


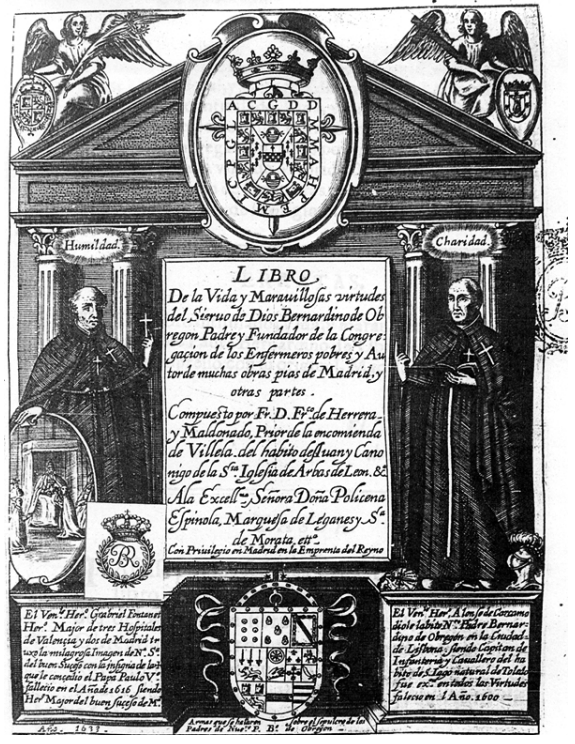

\section{Ilustración 6.}

lustración del Libro de la vida y maravillosas virtudes del Siervo de Dios Bernardino de Obregón, de Francisco de Herrera y Maldonado. Impresa en Madrid en 1633. Fondo: Archivo y Biblioteca Qalat Chábir A.C. Alcalá de Guadaíra.

\section{EL CRECIMIENTO DE LAS FUNDACIONES. LOS OBREGONES LLEGAN A ANDALUCÍA}

Bernardino de Obregón llevó a cabo una amplia tarea de fundaciones de hospitales en toda la Península Ibérica, incluyendo España y Portugal, y que después de su muerte se extendería por otras localidades de Europa y el Nuevo Mundo. Con las fundaciones llegaba una forma de cuidar a los enfermos, en el plano físico y en el plano espiritual. Con sus enfermeros llegaba a cada hospital fundado o aceptado para su administración la práctica enfermera enseñada por el mismo Bernardino. Por ello, conocer la expansión de la congregación es conocer, de forma paralela, la presencia de la enfermería obregoniana en estos lugares ${ }^{6}$.

6 En los grandes hospitales dirigidos por los enfermeros Obregones, como el Hospital General de Madrid, solían acoger a niños y niñas abandonados y se les proporcionaba instrucción y se les mantenía hasta tener edad de ocuparse en un oficio o tomar estado (casarse, entrar al servicio de señoras principales o entrar en religión), cuando de niñas se tratase. García Martínez, Antonio C.: "Hospitales en la España del siglo XVI, esos"otros" centros de enseñanza. Las preocupaciones de Bernardino de Obregón por la infancia". En Elena E. Rodríguez Díaz y Antonio Claret García Martínez (Eds.). Historia y Archivos. Estudios en homenaje a 


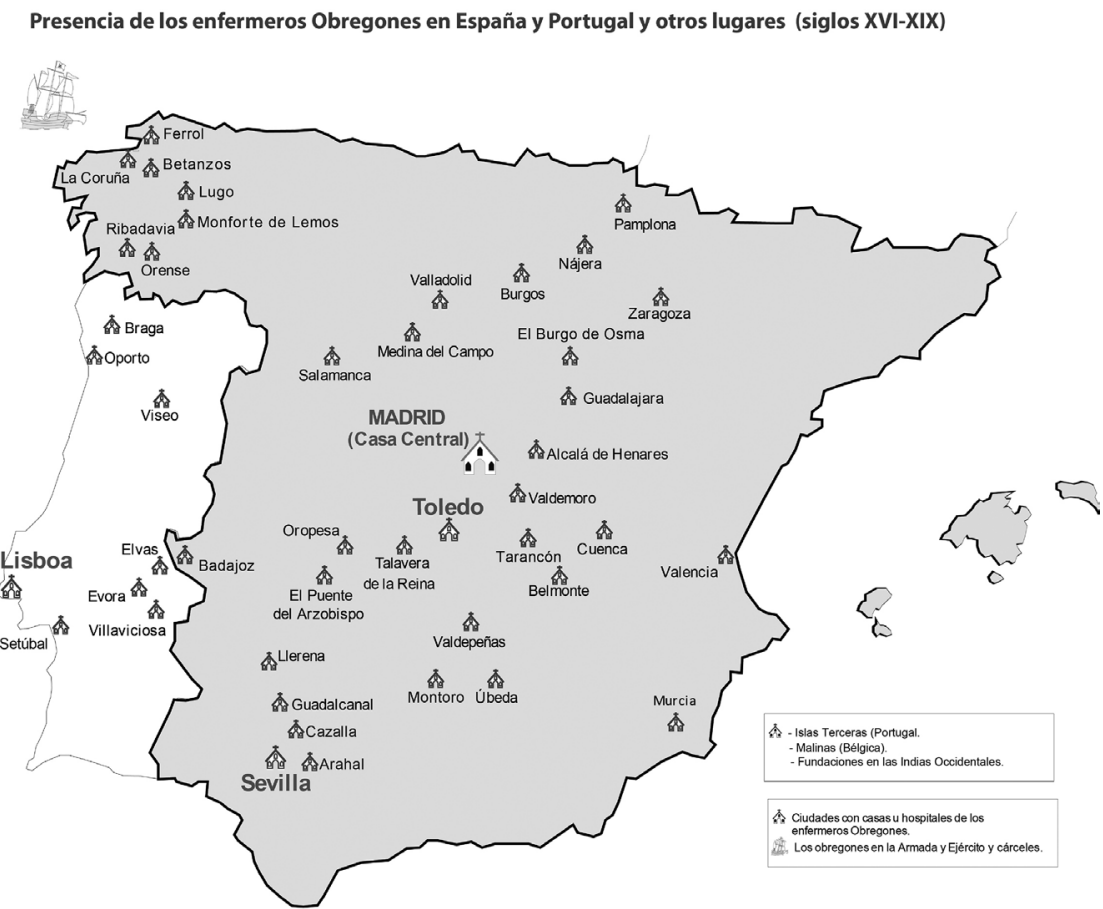

Ilustración 7.

Presencia de los enfermeros Obregones en España y Portugal. Elaboración propia.

Entre los siglos XVI, XVII y XVIII los enfermeros Obregones estuvieron presentes en más de 50 centros hospitalarios, ubicados en grandes ciudades, pero también en pequeñas localidades, de tal manera que la presencia de la enfermería obregoniana tejió una tupida red de centros asistenciales de gran consistencia, que llegó a influenciar en otros muchos centros asistenciales cercanos y en congregaciones de enfermeras hasta el siglo XIX.

A mediados del siglo XVII, la presencia de los enfermeros Obregones era una realidad en casi toda la Península Ibérica y su prestigio hacía que fueran requeridos sus hermanos en muchos hospitales y servicios (Armada, Ejército, cárceles, domicilios particulares y hospitales de cofradías).

Dña. Remedios Rey de las Peñas. Servicio de Publicaciones Universidad de Huelva.

Huelva, 2020, págs. 47-80. 
Las fundaciones en Andalucía fueron en Guadalcanal, Cazalla de la Sierra, Arahal, Montoro, Úbeda y Sevilla capital.

Las tareas de fundación en Sevilla se iniciaron hacia 1633, cuando la Congregación proyectó la creación de un hospital para la convalecencia de los enfermos que salían de otros hospitales sevillanos, pero cuya recuperación no era completa, lo que les hacía recaer con frecuencia. Este hospital de convalecientes se fundó bajo la advocación de Ntra. Sra. del Buen Suceso y estuvo situado en la collación de San Pedro.

Las tareas de fundación en Sevilla fueron complejas, a cuyo cargo estuvo el hermano Carlos de Urreón, comisionado por el Hermano Mayor del Hospital General de Madrid. Las tramitaciones necesarias fueron precedidas del establecimiento de contactos con importantes personalidades e instituciones locales.

Sobre los inicios de la presencia de los enfermeros Obregones en Sevilla para la fundación de un hospital conocemos dos documentos manuscritos: uno, localizado en el Archivo General del Arzobispado de Sevilla ${ }^{7}$, y otro, en el Archivo Histórico de la Diputación Provincial de Sevilla ${ }^{8}$, recogiéndose en ambos de manera pormenorizada las actuaciones seguidas por los enfermeros Obregones desde 1634 para llevar a efecto tal fundación.

Comienza el documento recogiendo que el matrimonio formado por D. Alonso García Vázquez Roldán, familiar del Santo Oficio, y Dña. Ana Garcés, vecinos de la collación de San Salvador de Sevilla, reconocen que son muy devotos de Nuestra Señora del Buen Suceso y en señal de agradecimiento por las gracias recibidas construyen un tabernáculo y una pequeña capilla en la calle Executor Vega, de dicha collación, exponiéndose en ella una imagen de dicha advocación, propiedad del matrimonio. Poco después, el matrimonio promueve la fundación de una cofradía con la advocación de Ntra. Sra. del Buen Suceso, con celebración de una fiesta principal el día 8 de septiembre. Con ello, la devoción a Ntra. Sra. del Buen Suceso creció en la ciudad de forma considerable. Poco después, para procurar que “[...] los pobres que salen de los hospitales de esta ciudad para convalecer

Archivo General del Arzobispado de Sevilla (AGAS). Serie Justicia-Ordinario. Legajo n. ${ }^{\circ} 3.996$ (signatura nueva) y 4.271(signatura antigua).

8 Archivo de la Excma. Diputación Provincial de Sevilla. Hospital del Buen Suceso. Legajo 1 ("Libro del Protocolo del Hospital de Combalecientes titulado de Ntra.

Sra. del Buen Suceso". 
tuviesen casa para poderlo hacer [... $]^{\prime \prime}$, decidieron construir un hospital para convalecientes que llevaría el mismo nombre de esta advocación mariana.

Por entonces, la capital hipalense carecía de centros de estas características, por cuya causa no eran pocos los enfermos que recaían de sus dolencias y morían. Por ello se veía necesario que:

"[...] se fundase un hospital de convalecientes de que esta dicha ciudad carecía, por cuya causa los dichos enfermos que salían convalecientes de los hospitales della, respecto de ser como todos y la mayor parte son pobres y nesesitados y no tienen donde recoxerse ni con que curarse en su convalecencia, nuevamente recaen en ella, poniéndose con la recaída de sus enfermedades en mayor peligro de perder la vida en que antes habían estado por la dicha enfermedad"10.

El 25 de octubre de 1635 el hermano Urreón elevaba solicitud al Cabildo y Regimiento de la ciudad de Sevilla pidiendo licencia para fundar el Hospital de Convalecientes de Ntra. Sra. del Buen Suceso, obteniendo las licencias correspondientes, y, finalmente, el 12 de mayo de 1636 se firmaba el documento en donde se estipulaban las condiciones en que se concedía la licencia fundacional.

Tras la presentación del hermano Carlos de Urreón y su reconocimiento por parte de la Congregación como persona comisionada y con plenos poderes para llevar a cabo la fundación, se procedió a la adquisición del inmueble, concertándose que todo lo necesario para dotar al hospital de equipamiento correría a cargo del hermano Carlos de Urreón y de su Congregación, dedicada, según el citado documento, a la hospitalidad de incurables, asistencia en caso de peste y otras enfermedades, atender en cárceles y armadas reales y ayudar a bien morir. Asimismo el concierto incluía un aspecto importante, el relativo al número de hermanos enfermeros que atendería el Hospital, que sería entre cuatro o seis ${ }^{11}$.

9 AGAS. Serie Justicia-Ordinario. Legajo n. 3 3.996, Documento: «SELLO PRIMERO...», f. 3 .

10 AGAS. Serie Justicia-Ordinario. Legajo n. 3 3.996, Documento: «SELLO PRIMERO...», f. 3 .

11 AGAS. Serie Justicia-Ordinario. Legajo n. ${ }^{\circ}$ 3.996, Documento: «SELLO PRIMERO...», f. 8 . 


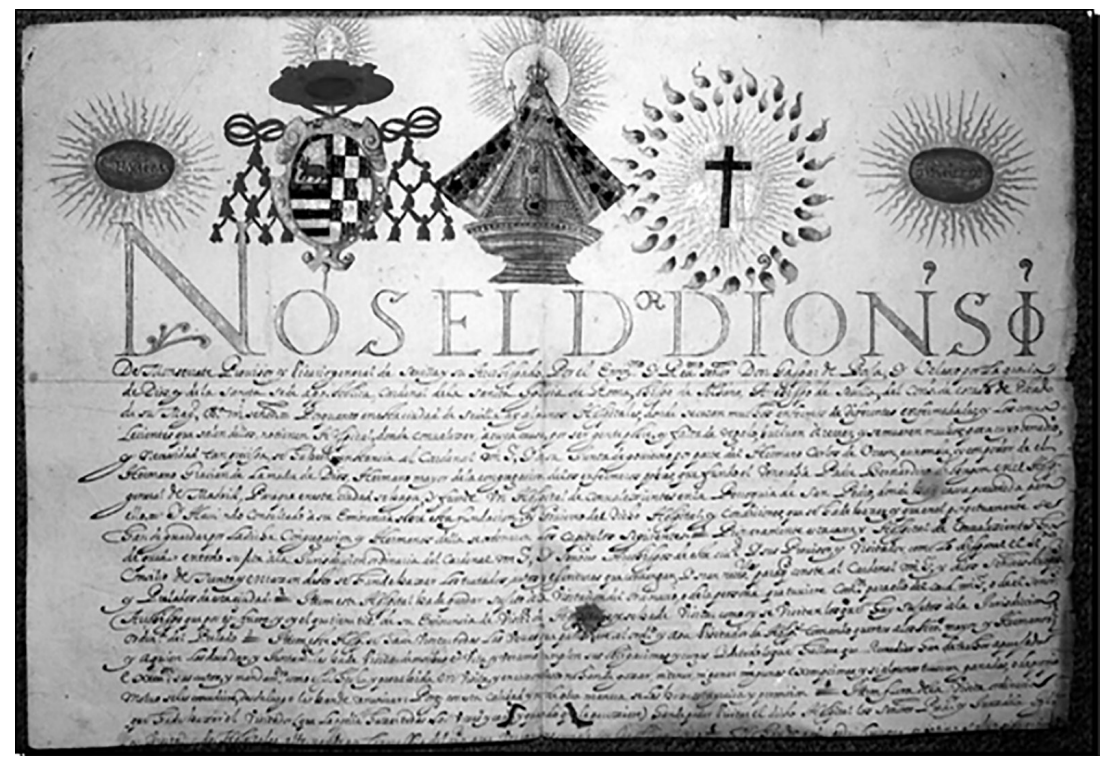

Ilustración 8.

Documento fundacional del Hospital de Convalecientes Ntra. Sra. del Buen Suceso de Sevilla, año 1639. AGAS, Legajo 3.996.

Los documentos referidos, además de recoger todas las intervenciones necesarias para llevar a cabo una fundación hospitalaria, ofrecen una visión de las necesidades sanitarias de la Sevilla de la época.

Otro documento inserto en el anterior recoge el nombramiento de Carlos de Urreón como Hermano Mayor del Hospital de Convalecientes de Ntra. Sra. del Buen Suceso, fechado asimismo en el Hospital General de Madrid el 18 de agosto de 1636, ante el escribano real Hermenegildo de Pineda. El Hermano Mayor General de la Congregación, el hermano Theodosio Machado, en nombre de todos los hermanos de Cruz, Consiliarios y Secretario nombra, con «pleno consentimiento y aplauso de todos», por Hermano Mayor del Hospital sevillano a Carlos de Urreón, dándole toda facultad, además, para que tenga a su cargo el gobierno y haga las visitas de los dos hospitales que en Sevilla había fundado la Congregación, localizados en Cazalla y Guadalcanal, pudiendo recibir los hermanos que fueren necesarios para su servicio. Esa facultad otorgada al hermano Carlos de Urreón le autorizaba también para poder hacerse cargo, en nombre de la Congregación, de cuantos hospitales se le ofrecieren en "Andalucía baxa", representar a su instituto en cuantos pleitos se 
presentaren y, en general, para cualquier asunto relacionado con la Congregación de los enfermeros Obregones en Andalucía:

"[...] y asi mesmo, le nombramos porVisitador General de los dichos hospitales que al presente, como dicho, le tiene esta santa Congregación en las villas de Cazalla y Guadalcanal y de todos otros qualesquiera hospitales que se dieren y encargaren y entregaren a nuestra Congregación en el partido de Andalucía baxa y admitir y admita qualquier hospital que le quieran entregar conforme nuestros estatutos, recibiendo todos los bienes que con ellos fueren entregados, poniéndolos por inventario. $Y$ admita a nuestra santa Congregación qualquiera hermanos convinientes y dalles hábito y poner y mudar de unos hospitales a otros los que le pareciere, nonbrándoles en los oficios para los que les hallare suficientes, y quitar hábitos a los que no fueren convinientes, escluyéndolos de nuestra Congregasión. Y en quanto a mudanza de hermanos, lo ha de poder hacer todas las veces que le pareciere, con causa o sin ella, según que nosotros lo podíamos y podemos hacer, que para ello le damos nuestras veces con amplia y plena facultad.

Y reciba en su poder y se dé por entregado de lo que perteneciere a los hospitales que le fueren entregados para encargallo por quenta e inventario a los hermanos que pusiere en ellos con claridad y distinción de todo [...]. Otrosí, le damos este dicho poder generalmente para en todos los pleytos, causas y negocios, civiles y criminales, eclesiásticos y seglares, que se ofrezcan y puedan ofrecer contra qualesquier personas $[\ldots]^{\prime \prime 12}$.

Recibidas las autorizaciones necesarias, se procedió a la construcción del hospital, resultado de la adquisición y adaptación de edificios existentes en la ciudad (casas-palacio), con obras de mejoras que podían extenderse durante varias décadas. Así ocurrió con el hospital de Convalecientes:

“Hospital de Ntra. Sra. del Buen Suceso. De la Congregación de Obregones. [...] La epidemia de 1649 detuvo algún tanto los progresos de esta fundación, pero no amenguó su importancia, pues los Hermanos Obregones adquirieron otra finca, labrando el edificio Hospital, que contenía un patio regular con arcos y columnas de mármol, buenas enfermerías para los convalecientes y las oficinas necesarias.

12 Ibíd, ff. 48-49. 


\section{Ilustración 9.}

Detalle del retablo mayor de la Iglesia de Ntra. Sra. del Carmen del Buen

Suceso (Sevilla). La escena refleja al hermano obregón Gabriel de Fontanet mostrando al Papa Paulo $\mathrm{V}$ la imagen encontrada en su viaje a Roma. Desde este año de 1606 la imagen sería conocida como Ntra. Sra. del del Buen Suceso. Fondo: Archivo y Biblioteca Qalat Chábir A.C. Alcalá de Guadaíra.

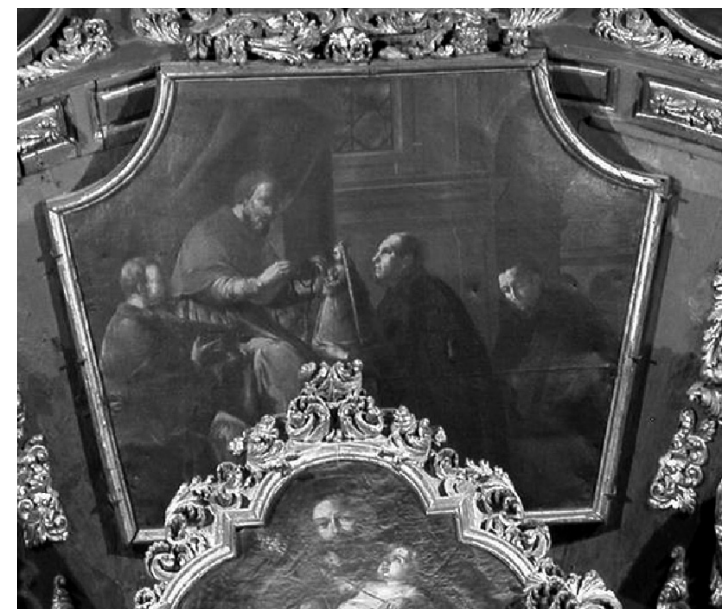

La obra de su Iglesia continuó más lentamente, pues su estreno se verificó el día de la Natividad de Nuestra Señora, 8 de Septiembre, de 1730, y fue la primera que tuvo la Congregación en España $[\ldots]^{113}$.

La presencia de los hermanos enfermeros Obregones en la capital hispalense duró algo más de dos siglos, desde su fundación en 1635, hasta mediados del siglo XIX; si bien en los últimos años su presencia puede considerarse como meramente testimonial, de conservación del edificio, ya en estado ruinoso y con muy pocos hermanos enfermeros, a lo sumo de uno a tres.

A principios del siglo XIX, durante la invasión francesa, el Hospital de Convalecientes atendía a enfermos y heridos militares de la guerra. Posteriormente, dejaría ya de cumplir definitivamente su función como centro para convalecientes, iniciándose su desaparición. Los sucesivos procesos desamortizadores llevados a cabo en esta centuria, que concluye con la Ley General de Exclaustración de las comunidades religiosas en 1835, aceleraron este proceso de decadencia.

En su proceso de expansión por Andalucía, los enfermeros Obregones se hicieron cargo en 1664 mediante escritura de concordia de la asistencia del Hospital del Santo Cristo de la Caridad y

13 Collantes de Terán, Francisco (1884). Memorias históricas de los Establecimientos de caridad. Descripción artística de los mismos. Imp. y Lit. de José M. ${ }^{a}$ Ariza. Sierpes, 19. Sevilla, pp. 231-240. 
Misericordia de Arahal, concierto que renovarían en el siglo siguiente, en 1743 , con un nuevo patronazgo a cargo de D. Juan Leonardo Malo Manrique ${ }^{14}$.

El Hospital de la Caridad y Santo Cristo de la Misericordia fue fundado en 1516 por la Cofradía de la Caridad y Misericordia de Arahal (Sevilla), teniendo como objetivos la asistencia a enfermos y pobres ${ }^{15}$. Desde su fundación hasta el año 1639, fecha en que llegaron los Hermanos del hábito de San Pablo, estuvo a su cuidado unos santeros que dependían de la Hermandad, la que les pagaban su sueldo. Los Hermanos del hábito de San Pablo fue la primera comunidad religiosa que pasó por el Hospital, permaneciendo en él sólo siete años, desde 1639 hasta 1646. Como queda dicho, en 1664 se hizo cargo la Congregación de enfermeros Obregones, que permanecieron en la localidad hasta las primeras décadas del siglo XIX ${ }^{16}$.

Arahal, al igual que otros lugares cercanos, se vio infectado con sucesivas epidemias, como la que sufrió desde el mes de enero de 1801 por"tabardillo" (tifus) y posteriormente de "terciana". Los enfermeros Obregones tuvieron que enfrentarse a todas estas situaciones.

Así, un pleito entre los hermanos Obregones y los curas de la villa refiere las actuaciones en materia de enterramiento en momentos de epidemia ${ }^{17}$. Los inspectores de epidemias y demás facultativos

14 La Hermandad posee un conjunto de libros manuscritos fechados en los siglos XVII y XVIII, que recogen la contabilidad de los enfermeros Obregones durante los años que estuvieron asistiendo en este hospital.

15 Martín Martín, Rafael: La Iglesia del Santo Cristo de Arahal. Historia y Arte. Hermandad del Santo Cristo de la Misericordia. Excma. Diputación Provincial de Sevilla. Sevilla, 2000.

16 Para conocer la historia de la Cofradía de la Caridad y Misericordia y del Hospital del mismo nombre, puede consultarse la página web "Real, Ilustre y Venerable Hermandad de la Santa Caridad y Misericordia, Cofradía de Nazarenos del Sto. Cristo de la Misericordia y María Santísima de los Dolores", cuya dirección es: http://www.iespana.es/hdad-misericordia/index.htm, y la obra de Rafael Martín Martín: La Iglesia del Santo Cristo de Arahal. Historia y Arte, editada por dicha Hermandad y la Excma. Diputación Provincial de Sevilla. Sevilla, 2000.

17 Archivo General del Arzobispado de Sevilla. Signatura: "Hermandades. Arahal. Obregones". Legajo n. ${ }^{\circ}$ 218. Año 1801. "Pleito entre el Hermano Mayor de los Obregones del Hospital de El Arahal y los curas de la villa". Escrito dirigido al Sr. Obispo Governador de parte del Síndico y Procurador General y el Hermano Alexandro de los Dolores, Mayor de la Casa Hospital de la Santa Misericordia de la Villa de El Arahal, solicitando se reponga la tapia del cementerio del Hospital, derribada por los vecinos tras la epidemia de tabardillo habida en 1800, entre 
que intervinieron en el asunto, en su informe de 14 de diciembre, recomendaban que:

"Lo esencial es que los cementerios de dentro de las poblaciones y bóvedas donde se han enterrado epidemiados después de saumadas éstas y las yglesias con bapores de ácido de sal marino y de echar alguna cal viva, se deberán terraplenar y cerrarse para siempre indispensablemente, pues no ay punto de inficsión que pueda compararse con éstos ni que ofrezca un riesgo tan yminente y ebidentíssimo de poderse prodigar la enfermedad que acava de devorar los pueblos y puede conducir y estenderse por toda la Europa y el mundo"18.

En efecto, los subinspectores de sanidad que visitaron Arahal para poner en prácticas tales medidas higiénicas y preventivas, actuaron sobre el Hospital, concretamente sobre su iglesia, lugar elegido para los enterramientos, y el cementerio:

"poniendo más de tres quartas de tierra sobre su terraplen antiguo, se tabicaron puertas y arcos que caían a un corredor contiguo a la Yglesia i, cerrando la bóbeda que se alla en ella, quedó obedecida la orden a satisfacción del vecindario y desde entonces se señaló enterramiento común fuera de la población, como a sesenta pasos de ella, contiguo a una ermita, y se dio facultades a dos conventos de religiosos extramuros, y unidos a seis u ocho pasos de la población y unidos a sus claustros, señalasen cementerios al decubierto y ventilados donde se acogiesen todos los que falleciesen, como assí se está practicando sin distinción de estado, clases, ni condiciones, más que pagar cierta cota señalada"19.

El conflicto entre los hermanos obregones y los curas de la villa vino porque estos, por su cuenta y sin los permisos oportunos, eclesiásticos ni civiles, derribaron el tabique levantado en la iglesia e "introdujeron a deshoras cuerpos en la Yglesia del citado hospital, sin noticia de su Hermano Mayor, ni menos de la Junta e Intervención puesta por el Supremo Consejo de Castilla [...]".

En el fondo, el asunto tenía un trasfondo puramente económico, dado que, al suspenderse los enterramientos en la iglesia, los curas dejaban de percibir las cantidades de dinero estipuladas, además de

otros asuntos. Lugar: Hospital de la Santa Misericordia de la Villa de el Arahal.

Fecha: 15 de septiembre de 1801.

18 Ibídem.

19 Ibídem. 


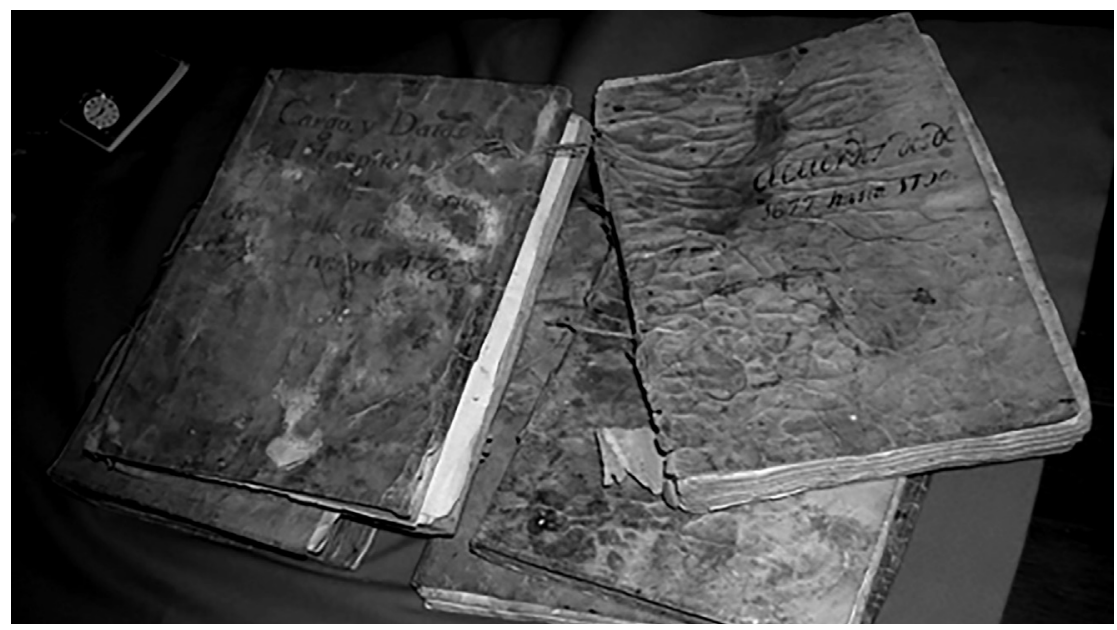

Ilustración 10.

Libros de cuentas del Archivo de la Hermandad de la Caridad y Misericordia del Santísimo Cristo de la Misericordia de Arahal (Sevilla).

Fondo: Archivo y Biblioteca Qalat Chábir A.C. Alcalá de Guadaíra.

las limosnas correspondientes que todo acto de esta trascendencia conllevaba. El hecho del derribo del tabique se describe del siguiente modo:

"Los curas, ageno de todo, buelta la espalda, el citado Síndico General en el mismo día que fue el trece del corriente, sin reparar en la solemnidad del Domingo, passaron por medio de trauajadores derribaron el tavique de un arco que caía a el camposanto, biolentaron otra puerta que correspondía a la calle, condenada por el Govierno público desde la epidemia, dando comunicación por [...] del todo cementerio a lo interior y condenando el postigo que servía de entrada y habían abierto los curas por su acomodo a costa de la fábrica" ${ }^{20}$.

La solicitud concluía pidiendo a la autoridad eclesiástica ordenase, a través del Sr. Vicario o al Mayordomo de Fábrica, se levante de nuevo el tabique derribado, además de hacer saber a los curas y sacristanes del pueblo que no llevasen a cabo nuevos entierros en la Iglesia del Hospital.

20 Ibídem. 


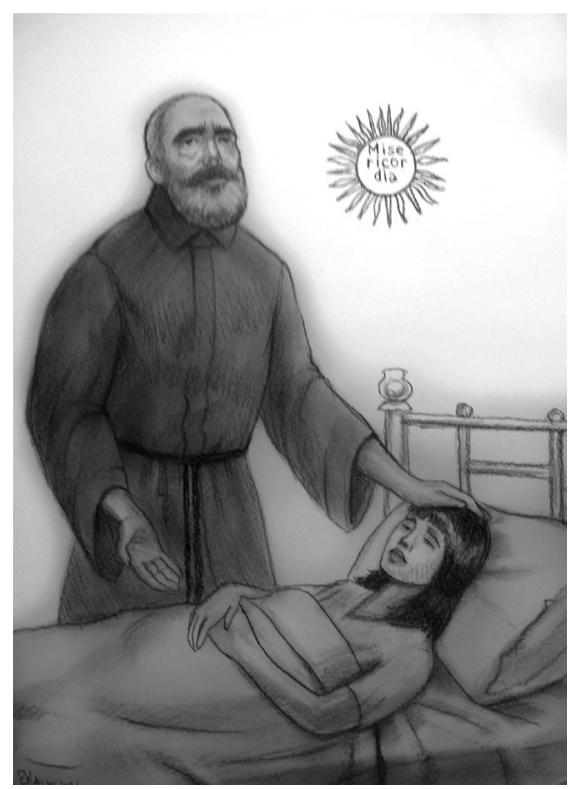

Ilustración 11.

E. Kabirov: Bernardino de Obregón (1599). Ayuda a bien morir.

Fondo: Archivo y Biblioteca Qalat Chábir A.C. Alcalá de Guadaíra.

Situaciones como la vivida en Arahal fueron las habituales en otras muchas localidades de los alrededores y las epidemias padecidas modificaron profundamente los hábitos higiénicos en torno a los cementerios, mantenidos así desde tiempo inmemorial.

Documentos como el referido reflejan las actuaciones de los hermanos Obregones en materia de salud en las localidades en donde se instalaban.

En todos los lugares en donde ejercían, los enfermeros obregones aplicaban los conocimientos y técnicas de enfermería proporcionados por su congregación en una etapa formativa inicial que pasaban todos los novicios que ingresaban en la institución ${ }^{21}$.

Además, desde 1617 y 1625 contaron con los tratados para enfermeros compuestos por la propia congregación e impresos en Madrid y que circularon por toda la Península, incluidas España y Portugal.

21 García Martínez, A. C.:"Las funciones de enfermería en los hermanos Obregones (siglos XVI-XVII). Docencia e investigación". En I Congreso de Historia de la Enfermería. Valencia, 1996, pp. 99-108. 


\section{SEGUNDA PARTE}

\section{LAS PROPUESTAS EN MATERIA DE SALUD DE LOS ENFERMEROS OBREGONES EN TIEMPOS DE EPIDEMIAS}

\section{LAS EPIDEMIAS QUE ASOLARON ANDALUCÍA}

Desde su instalación en tierras andaluzas, los enfermeros Obregones se enfrentaron directamente con las grandes enfermedades contagiosas que padecieron las ciudades del Sur del Reino, especialmente con la gran epidemia de peste de 1649, que marcó un momento de inflexión en la decadencia de la propia ciudad, desde el punto de vista demográfico y económico ${ }^{22}$.

En la época en que vivió Bernardino de Obregón, la segunda mitad del siglo XVI, la Península Ibérica sufrió grandes epidemias, especialmente la de 1596-1602 ${ }^{23}$, conocida como "peste atlántica", que causó su propia muerte en 1599. Por ello, el propio Bernardino estuvo toda su vida especialmente sensibilizado con estas enfermedades maliciosas e incluyó en su ideario de enfermero la lucha contra ellas.

Andalucía, y especialmente Sevilla ${ }^{24}$, también padeció las sacudidas de esta epidemia desde 1598:

"[Año 1598].

[...] En este [año] comenzó a afligir a Sevilla peste, que duró tres, hasta el año de 1601."25

22 Hernández Palomo, José J. (Coord.): Enfermedad y muerte en América y Andalucía (siglos XVI-XX). C.S.I.C. Escuela de Estudios Hispano-Americanos. Sevilla, 2004.

23 Betrán Moya, José L.: Historia de las epidemias en España y sus colonias (13481919). La Esfera de los Libros. Madrid, 2006.

24 Carmona García, Juan I.: La peste en Sevilla. Ayuntamiento de Sevilla. Área de Cultura. Sevilla, 2005 y del mismo autor La Enfermedad y Sociedad en los primeros tiempos modernos. Secretariado de Publicaciones. Universidad de Sevilla. Sevilla, 2005.

25 Ortiz de Zúñiga, Diego (1796). Anales Eclesiásticos y Seculares de la muy Noble y muy Leal ciudad de Sevilla, Metrópoli de la Andalucía. Con Licencia. Madrid, en la Imprenta Real. Año de 1796. Tomo IV. Guadalquivir, S. L. Ediciones. Sevilla", p. 193. 
"Año 1601.

1. [...] Proseguía en este año la peste aun más rigurosa que los pasados, con muerte de muchas personas conocidas y muchedumbre de pueblo. Curábase este en el gran Hospital de la Sangre a expensas públicas, en que la Ciudad gastó gran tesoro y duraba en él hasta casi nuestros tiempos un quarto tabicado lleno de la ropa de los que morían apestados, y de la que sirvió a sus camas, que en la peste de 1649 con más acierto se entregó al fuego." 26

Ortiz de Zúñiga relata prolijamente los acontecimientos de la gran peste de 1649:

“3. Desde el año de 1646 picaba la peste en los puertos de Andalucía, venida de las partes más Orientales, según se afirmaba, y las pudo temer Sevilla tanto como refería el año pasado, que se guardaba con gran vigilancia, mayor en este año porque, enferma ya la Ciudad en el invierno de achaques frequentes, aunque no se declaraban contagiosos, lo estuvo más en la primavera y sobreviniendo en ella a 4 de Abril repentina inundación de Guadalquivir por demasía de lluvias que bañó lo más de Triana y arrabales y de que aunque se defendió Sevilla no pudo de sus internas aguas a que cerrada la salida (como siempre) los mismos reparos que defendían la entrada a las del río, con que la demasía de humedades exhalando vapores nocivos con el calor que luego se siguió, añadieron causas de corrupción a las que ya influían en el ayre los astros segundas causas que todos amagaban pestilente epidemia, alterándose generalmente las complexiones mediante la respiración del ayre inficionado con que al principio ni aún los que después escaparon de la mayor eficacia del contagio se libraron de vahídos, nauseas y otros accidentes de estómago que fueron presagos del daño venidero en el mismo tiempo de la inundación $[\ldots]^{\prime 27}$.

Y una vez desatada la epidemia en la ciudad, el terror inundaba sus calles, casas y hospitales:

“Entretanto la vigilancia de los Ministros, animosos en lo más duro del peligro, disponía varios medios a la cura y conducción de enfermos al Hospital y de los muertes de este y de la Ciudad a los osarios y carneros, número grande carros y sillas de manos los iban incesablemente llevando; pero a muchos llegaba primero la muerte y a no pocos cogía en el camino, y de los que morían en las casas amanecían cada día llenas las calles y las puertas de las Iglesias: todo era horrores, todo llantos, todo miserias; faltaban

$26 \quad$ Ibíd., p. 205.

$27 \quad$ Ibíd., p. 397. 
Médicos, no se hallaban medicinas, los regalos aun a exorbitantes precios no se conseguían, valiendo tres ducados y a veces quatro una gallina, uno un pollo y a dos o tres reales un huevo, y al respecto los demás y todos los mantenimientos, aunque la comarca estaba abundante y abastecida; pero negábanse a la conducción los forateros con el horror del riesgo y crecía en los demás la codicia, aunque diferentes Ministros salían a hacerlos venir y a que se conduxecen el pan, carne y otros géneros precisos, con admirable prontitud y desvelo, en tanto que la muerte se cebaba de tal modo en todos estados que había día que pasaban de dos mil y quinientos los muertos en los Hospitales y casas particulares y aunque se llenaban las bóvedas de las Iglesias, de que ninguna se reservó (que no era tiempo de mirar en patronatos ni respetos) ya no cabían ni en los cimenterios ni en los carneros del Hospital" 28 .

Una nueva referencia a los Anales de Ortiz de Zúñiga muestra los límites de la tragedia de la gran epidemia:

"En la Sacristía de la Ermita de San Sebastián se conserva una inscripción que dice el número de carneros que hubo el año de la peste en el campo próximo a la ermita y el de cadáveres que se enterraron en ellos, cuyo contenido dice así:

\author{
"Yacen enterrados en 27 carneros que están \\ dentro y fuera de esta Hermita 23.443 cuerpos \\ de difuntos en la epidemia que el año de 1649 \\ padeció esta Muy Noble y Leal Ciudad de Sevilla. \\ Hicieron poner esta memoria el Mayordomo y Hermanos \\ del glorioso Mártir San Sebastián para dispertar \\ en los fieles el temor de Dios y la memoria de \\ pedirle por los difuntos a su Magestad".
}

Los primeros temores llegaban a la población con las noticias del contagio en alguna parte del Reino, con frecuencia en ciudades portuarias. Reconocido y declarado el brote, la Corona solía comunicar la noticia a través de bandos a las autoridades locales de las grandes ciudades, primero, y de las localidades más pequeñas a través de estas, después. Un gran temor se iba apoderando de la población.

Las primeras medidas conforme se acercaba la epidemia a los territorios iban encaminadas al control de acceso a las ciudades: control de las personas y de las mercancías y refuerzo de la vigilancia en

$28 \quad$ Ibíd., p. 398. 
todas las puertas de la ciudad. Cuando fallaba este primer control y el brote ya se encontraba localizado en el interior de la ciudad, también se producía el control de salida.

Con el brote ya detectado en el interior de la ciudad, el terror se apoderaba de la población y se iban señalando los hogares y las familias contagiadas. Una espiral de enfermedad, dolor y muerte comenzaba a inundar la atmósfera. Los hospitales de la ciudad aumentaban sus ingresos de enfermos. Las grandes ciudades solían erigir un hospital apartado para acoger a los enfermos contagiados o con sospechas de padecer la enfermedad.

Y continúa Ortíz de Zúñiga hablando sobre la peste de 1649:

"No había ya cabida en los Hospitales, y hubo noche de quedarse en el campo del Hospital de la Sangre más de quatrocientos, y, habiendo sido la noche de agua y frío, amanecieron muertos más de trescientos. Murieron los más de los Religiosos de San Juan de Dios, y los Hermanos del BuenSuceso, de las demás Religiones y Clerigos más de cinco mil; de criados del Cabildo, más de doscientos y, si fuera a ir refiriendo los desatres que sucedieron, sería muy dilatado" 29 .

Las condiciones socio-sanitarias de la Sevilla del quinientos eran muy deficitarias y las calles y espacios existentes representaban un marco propicio para la presencia de insectos, suciedad e inmundicias:

"La capital de la Giralda presentaba efectivamente idéntica situación de nocividad ambiental en el transcurso de los primeros tiempos modernos [la compara con Madrid]. Hay que recordar que se trataba de un entorno urbano dominado por la falta de limpieza pública y privada, con un sistema de desagüe deficiente y defectuoso, con una red viaria mal pavimentada y tortuosa, con unas calles frecuentemente inmundas, polvorientas unas veces, embarradas otras, con numerosos muladares y rincones convertidos en estercoleros.

Todo esto propiciaba la aparición de gérmenes infecciosos y la presencia de animales e insectos que representaban un peligro evidente para la salud de los habitantes, aunque solo fuera porque aquellos se constituían en los vehículos (vectores) idóneos para la propagación de enfermedades. En efecto, perros y gatos, mosquitos y roedores, pulgas y piojos se movían abundantemente en aquel ambiente insano, siendo la suciedad dominante

29 Ibíd., pp. 139-140. 
un buen caldo de cultivo para que a través de estos agentes se transmitiesen los males y las afecciones contagiosas" ${ }^{\prime 30}$.

Con todo ello, la llegada y rápida expansión de agentes patógenos encontraba un campo abonado para extenderse cuando se daban unas mínimas condiciones para ello, como resultado de inundaciones, calores excesivos o la llegada de esos agentes patógenos desde el exterior en forma de contagio ${ }^{31}$.

Hemos de conocer que las expresiones utilizadas en esta época de "peste", "pestilencia", "enfermedades pestilenciales", "enfermedades malignas" englobaban un conjunto amplio de patologías que hoy tiene la Medicina bien diferenciadas y reconocidas, pero que no lo eran en esta centuria por la situación de los avances científicos. Así, unas veces, cuando se hababla de "peste" reconocemos hoy a la identificada como "peste bubónica" (yersinia pestis); pero en otras ocasiones se hablaba de peste y también de "tabardillo"y se refería al tifus. En otras ocasiones se hacía referencia a las manifestaciones que las enfermedades epidémicas mostraban más visiblemente, como las "fiebres maliciosas", el"landre" 32 , el"tósigo"33, la"seca" ${ }^{44}$ y el"bubón"35.

El vocabulario que manejaban los enfermeros se completaba con una amplia terminología referida a diferentes patologías y sus síntomas, conocidas y reconocidas más por la experiencia de haberlas tratado que por una base científica. Entre ellas, destacaron el "anhélito corrupto, las calenturas -agudas, ardientes, continuas, largas, otoñales, pestilentes, cuartanas...-, el carbúnculo, el cólera, los chancros, las destilaciones del pecho, las disenterías, la empiema, las"erisipulas", la esquinencia, las de distinto tipo (algunas conocidas como

30 Carmona García, Juan I. La Enfermedad y Sociedad en los primeros tiempos modernos. Secretariado de Publicaciones. Universidad de Sevilla. Sevilla, 2005, p. 30.

31 A todo ello se unía el sustrato de pobreza que existía en amplias capas de la sociedad. Carmona García, Juan I.: El extenso mundo de la pobreza: la otra cara de la Sevilla Imperial. Servicio de Publicaciones. Excmo. Ayuntamiento de Sevilla, 1993.

32 Landre. (Del latín vulgar glando, -inis, por glans, bellota). Tiene el significado de bubón y peste bubónica. Dccionario Terminológico de Ciencias Médicas. Salvat

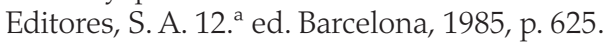

33 Tosigo.Veneno, ponzoña. RAE.

34 Seca. Inflamación dolorosa en algún ganglio linfático de la zona axilar o inguinal producida por una infección, como la aquí tratada de la peste. RAE.

35 Bubón. Tumor purulento y voluminoso, localizado especialmente en la ingle. RAE. 
"malignas"), las "fluxiones de humores", el garrotillo, los héticos, la lepra, los mocos sanguinolentos, las paperas, el sarampión, la sarna, las tercianas, la tisis, la tos, los tumores -de varios tipos-y los vapores malignos" ${ }^{\prime 36}$.

Todo ello constituía el espacio cotidiano de la enfermería y periódicamente el azote de las grandes epidemias ${ }^{37}$.

Ante esta situación, ¿qué protocolo de actuación desarrollaban los enfermeros Obregones en aquellos lugares en donde tenían hospitales? Para su respuesta utilizamos las obras ya mencionadas: las reglas de la Congregación, el tratado Instrucción de Enfermeros, el Tratado de ayuda al bien morir y las biografías de Bernardino de Obregón conservadas ${ }^{38}$.

Las medidas aplicadas para la asistencia a los enfermos infectados se realizaban en los domicilios de los enfermos, en los

36 García Martínez, Manuel J. Cuidar el cuerpo y salvar las almas: la práctica de la Enfermería según el modelo de la Congregación de enfermeros obregones. Tesis doctoral. Dirigida por el prof. Salvador Rodríguez Becerra. Universidad de Sevilla, 2007, pp. 124-125. Disponible en: http://hdl.handle.net/11441/15076

37 Fueron numerosos los tratados que sobre la peste y sus consecuencias se escribieron en los siglos XVI y XVII, que muestran los conocimientos científicos de la época y toda la concepción que se tenía sobre la enfermedad. Recogemos sólo algunos de ellos a modo de muestrario: Informacion y curacion de la peste de Caragoca y praeservacion contra peste en general, por Ioan Thomas Porcell Sardo (1565); Tratado de peste, donde se contienen las causas, preseruacion, y cura; con algunas questiones curiosas al proposito, por Juan Ximénez Sauariego (1602); El verdadero conocimiento de la peste, sus causas, senales, preservacion $i$ curacion, por Johan Francisco Rossel (1632); Tratado de peste, sus causas y curacion, y el modo que se ha tenido de curar las secas y carbuncos pestilentes que han oprimido a esta ciudad de Malaga este ano de 1637, por Juan Viana (1637). Véase Blanco Pérez, José I.: "Luis Mercado y la traducción de textos médicos en el Renacimiento: El libro de la peste". En Ferran Grau Codina y otros (Editores). La Universitat de València i l'Humanisme: Studia Humanitatis i renovaciò cultural a Europa $i$ al Nou Món. Departament de Filologia Clàssica. Universitat de València. Valencia, 2003. Véase también Sánchez, María Nieves (estudio y edición): Tratados de la peste. Arco/Libros, S. L., Madrid, 1993.

38 García Martínez, Manuel J.; García Martínez, Antonio C.: Orígenes y fundamentos de la Enfermería moderna en España. Los tratados "Instrucción de Enfermeros" y "Tratado de lo que se ha de hazer con los que están en el artículo de la muerte" (siglo XVII). Consejo General de Enfermería de España. 2. ${ }^{a}$ Edición, Madrid, 2019. También con edición en inglés bajo el título de The origins and foundatios of modern Nursing in Spain. The treatises "Instruction of Nurses" and "On what is to be done with those at the point of dead (XVII Century). Consejo General de Enfermería de España. Madrid, 2017, 436 pp. 
hospitales (en aquellas poblaciones que contaban con ellos) y, cuando era posible, en hospitales de aislamiento habilitados en situaciones de epidemia ${ }^{39}$.

Los enfermeros Obregones aplicaban cinco tipos de medidas, unas en coordinación con las autoridades locales y otras directamente a través de cuidados enfermeros más específicos dispensados en sus hospitales o donde ellos eran llamados a trabajar:

1. Medidas de aislamiento. A nivel de ciudad, a nivel de hospitales y a nivel de domicilios particulares.

2. Medidas de higiene de los enfermos y su entorno.

3. Medidas sobre la alimentación de los enfermos y de las personas sanas.

4. Medidas en base a los remedios médicos.

5. Medidas a través de los cuidados espirituales.

\section{MEDIDAS DE AISLAMIENTO. A NIVEL DE CIUDAD, A NIVEL DE HOSPITALES Y A NIVEL DE DOMICILIOS PARTICULARES}

Si bien había un gran desconocimiento en la época tanto de la naturaleza de los contagios como de los agentes patógenos causantes de los mismos (por ejemplo, la bacteria de la peste bubónica no fue identificada hasta finales del siglo XIX y tratada con éxito hasta comienzos del $X X)$, la experiencia en sucesivas oleadas epidémicas fue mostrando la eficacia de ciertas medidas; al menos, se intuían sus efectos y sus posibles remedios para reducir el contagio.

Entre las medidas iniciales que se aplicaban en las ciudades, primero, y en los domicilios y hospitales, a continuación, se encontraban la separación y el aislamiento de los enfermos con síntomas visibles

39 Un amplio estudio a este respecto puede verse en García Martínez, M. J.: "La hospitalización y la peste en el siglo XVII en Directorio de Enermeros, de Simón López". En Erebea.Revista de Humanidades y Ciencias Sociales, núm. IV (2014). Universidad de Huelva, pp. 119-144. Sobre aspectos generales de los cuidados enfermeros puede verse García Martínez, Antonio Claret; García Martínez, Manuel Jesús: Directorio de enfermeros. Un tratado para la formación de los enfermeros en la España del siglo XVII. Consejo General de Enfermería de España. Madrid, 2017. También con edición en inglés bajo el título de Directory for nurses. A treatise for the training of nurses in 17th century Spain. Consejo General de Enfermería de España. Madrid, 2017, 635 pp. 
de haber contraído la enfermedad, especialmente en los primeros días, que cursaban con fiebre alta, pérdida de apetito, la aparición de las primeras erupciones cutáneas y otras manifestaciones específicas de la enfermedad de que se tratase ${ }^{40}$.

El cierre de las ciudades para evitar la entrada y salida de personas se aplicaba como una de las primeras medidas, con las consecuencias derivadas de ello: escasez de recursos de todo tipo, sobre todo de alimentación.

Seguían el confinamiento domiciliario y, a nivel de hospital, la separación en salas de los enfermos sospechosos de haber adquirido la enfermedad.

Las noticias que recoge Ortiz de Zúñiga sobre la gran peste de 1649 son muy valiosas a este respecto.

"Y la Ciudad por sí hizo otra diputación [...] que atendían a lo más inmediato del gobierno y manejo y execución de las resoluciones, como obligación más propia suya, a que mirando, pidieron a los Patronos del Hospital de la Sangre sus nuevos quartos, como se hizo en la peste del año de 1600, que concedido como cosa tan del bien público se hallaron en su gran capacidad diez y ocho salas que aplicar a la curación, sin otras que se cercaron y cubrieron de tablas, no bastando aun tanta anchura para la multitud de enfermos que ocurrió" ${ }^{\prime 1}$.

"4. Creció la violencia de la epidemia entrando el mes de Mayo, y ya casi toda la Ciudad era un Hospital, porque a la inmensidad de todos estados que se hería y moría no bastaba la prevención del sitio destinado, aun fuera de la gente principal y caudalosa, que no podía ser sacada de sus casas. Aunque de esta se aumentó mucha, llenándose los lugares y casas de campo circunvecinas y en todo el Aljarafe" ${ }^{\prime 2}$.

Ya en la gran peste de 1600, las autoridades de la ciudad pidieron a los patronos del Hospital de la Sangre que habilitaran nuevas salas para acoger a los enfermos que en gran número ingresaban en el hospital, como también ocurrió en la epidemia de 1649. Del mismo modo, las personas se negaban a salir de sus casas por miedo al

40 García Martínez, Manuel J.: "La hospitalización y la peste en el siglo XVII en Directorio de Enfermeros, de Simón López. Erebea. Revista de Humanidades y Ciencias Sociales, 4 (2014). Universidad de Huelva, 2014, págs. 119-143.

41 Ortiz de Zúñiga..., p. 398.

42 Ibíd. 
contagio y aquellas familias acaudaladas que tenían residencias en la zona del Aljarafe huían ante la expansión de la enfermedad.

Sin embargo, estas medidas tenían escasos efectos beneficiosos una vez que se había expandido la epidemia por toda la ciudad.

\section{MEDIDAS DE HIGIENE DE LOS ENFERMOS Y SU ENTORNO}

Una de las aportaciones más importantes de la Congregación de enfermeros Obregones fue la adopción de medidas higiénicas en sus hospitales como base para la recuperacion de los enfermos: limpieza de las enfermerías dos veces al día; vaciado de los recipientes que contenían los fluidos biológicos -orina, heces y esputos- de los enfermos tantas veces como fuese necesario; cambio de ropa de los pacientes ingresados y de las camas debido a la sudoración provocada por la fiebre; ventilación de las enfermerías; aplicación frecuente de sahumerios con sustancias purificadoras, tales como el romero, para combatir los malos olores y aseo de los enfermos.

Todas estas medidas se incrementaban en caso de enfermedades consideradas contagiosas, como la peste, el tifus, la viruela, el paludismo, la tuberculosis, la sífilis o bubas y otras que, bajo el epígrafe de fiebres o calenturas, afectaron de manera importante a la población. Otras enfermedades, como la lepra o el ergotismo, conocida esta última como fuego de San Antón -intoxicación debida a la ingesta de un hongo, el cornezuelo del centeno, que producía convulsiones y gangrena de las extremidades-, se hallaban en franco retroceso en relación a su incidencia en el período medieval ${ }^{43}$.

Se procedía al cambio de las ropas de las camas y las camisas de los enfermos con mayor frecuencia de lo habitual, pasando a quemarse todo este ajuar hospitalario inmediatamente ante la sospecha de contagio de las personas en contacto con él. Cuando se producían los primeros fallecimientos, se realizaba el enterramiento inmediato de los cadáveres con capas de cal para destruir los agentes causantes.

43 García Martínez, Manuel J. Cuidar el cuerpo y salvar las almas: la práctica de la Enfermería según el modelo de la Congregación de enfermeros obregones. Tesis doctoral. Dirigida por el prof. Salvador Rodríguez Becerra. Universidad de Sevilla, 2007, pp. 124-125. Disponible en: http://hdl.handle.net/11441/15076 
"Segundo, si se ha de vestir camisa limpia.

Y, porque hemos començado a tratar de la limpieza, trataremos ahora si en las enfermedades maliciosas, como son viruelas, tabardillo y fiebres malignas, será bueno mudar ropa estando suzia, y respóndese que sí por razón que la camisa está con los vapores malignos que resultan de calenturas y, si se pusiesse a un sano, no sería mucho que, estando dispuesto, se le pegasse, ¿que menos razón hay que se le torne a pegar al enfermo? Luego, bueno será mudarle la ropa, como no sea en día de purga" ${ }^{44}$.

Se explica la técnica de cómo debían los enfermeros cambiar las sábanas:

“6. El poner de las sábanas.

Entre dos, tomar las sábanas cada uno por su punta, recogiendo en pliegues le meterán una punta por debaxo de la cabeça, sin descubrirle, y la otra por debaxo de los pies y, passando de la otra parte de la cama, tirándole por ella, se la podrán poner sin descubrirle ninguna cosa $[\ldots]^{\prime \prime 45}$.

Fundamentales se consideraban las medidas que debían aplicarse con los cadáveres. En los manuales de enfermería elaborados en la época se recogen la realización de fosas comunes a las que se añadía cal viva, quemándose en ellas las ropas y enseres de los enfermos fallecidos de peste, evitándose con ello también su venta pública y su circulación entre las personas sanas ${ }^{46}$.

\section{MEDIDAS SOBRE LA ALIMENTACIÓN DE LOS ENFERMOS Y DE LAS PERSONAS SANAS}

Los efectos de la pérdida del apetito de los enfermos hacían que en pocos días se llegara a la desnutrición, a la baja de defensas y a la muerte. Por ello, era fundamental fortalecer al enfermo a través de la alimentación lo más adecuada posible, evitando los alimentos que

44 Fernández, Andrés (1625). Instrucción de Enfermeros para aplicar los remedios a todo género de enfermedades y acudir a muchos accidentes que sobrevienen en ausencia de los médicos. Con privilegio. En Madrid, en la Imprenta Real. Año MDCXXV, p. 127.

45 Ib. pp. 129-130.

46 García Martínez, Manuel J. Cuidar el cuerpo y salvar las almas: la práctica de la Enfermería según el modelo de la Congregación de enfermeros obregones. Tesis doctoral. Dirigida por el prof. Salvador Rodríguez Becerra. Universidad de Sevilla, 2007, pp. 124-125. Disponible en: http://hdl.handle.net/11441/15076 
pudieran provocar rechazo del cuerpo en situaciones especialmente graves. En una sociedad en la que la mayor parte de la población vivía al límite de la subsitencia, garantizar un mínimo nivel diario de calorías era tarea nada fácil. Mientras los hospitales contaban con recursos suficientes y los mercados todavía estaban abastecidos, se procuraba proporcionar a los enfermos un nivel adecuado de alimentación.

Una vez contraída la enfermedad, era muy importante, por tanto, el mantenimiento nutricional en las mejores condiciones de los enfermos:

"20. Apetitos (alimentos) que se han de dar a todo género de enfermos para poder comer con sus principios y postres.

Y porque hay enfermos tan desabridos en el comer, diremos qué apetitos se puede dar a cada género de enfermos y las más comunes cosas que se han de guardar.

A los de tabardillo, carbúnculos, erisipulas y heridas de fresco no se les ha de dar peregil, salvo no habiendo otro remedio, por ser caliente y tener partes de unirse con la cólera y sangre y aumentarla más ${ }^{47}$; a los tales se les ha de dar çumo de limón o agraz y, lo mejor de todo, es el limón, por ser el agraz astringente; a los de dolor de costado no se les ha de dar ningún género de agrio, ni carne de membrillo, ni perada, ni fruta verde de ningún género, salvo estando ya en la declinación; si le quisieren dar quatro ciruelas bien maduras para principio y postre, puédese dar escorçonera ${ }^{48}$, alfeñique $^{49}$, calabazate ${ }^{50}$, bizcochos, ciruelas en conserva, açúcar de pilón ${ }^{51}[\ldots]^{\prime \prime 52}$.

47 Principios de las teorías de los humores, aun plenamente vigentes.

48 Planta muy común en España. Se aprovecha la raíz. Se consume cocida en guisos o en ensaladas, y salteadas en mantequilla. Tienen un sabor poco común. Nutricionalmente destaca por el alto contenido de vitaminas E, B1 y B2, de minerales como Hierro, Fósforo y Calcio (Fe, P y Ca). Se recomienda comerlas muy bien cocidas, al agua o al vapor, para hacerlas más digeribles. Se recomienda pelar las raíces después de cocidas, para que no pierdan sabor. También pueden consumirse las hojas, especialmente las jóvenes después de hervidas. Las "barbas", hojas tiernas, frescas y blandas, se pueden consumir crudas. Los brotes tiernos se usan a modo de espárrago. Las flores se añaden a las ensaladas como aromatizante; tienen un aroma que recuerda al cacao. También se pueden utilizar los capullos florales.

49 Alfeñique es una especie de caramelo o confitura procedente de España con base en azúcar pura de la caña preparada en pasta alargada y retorcida. DRAE.

50 Dulce hecho con trozos de calabaza hervidos con azúcar. DRAE.

51 Azúcar pilón o azúcar refinado o incluso azúcar de grano grueso es el azúcar más refinado que hay y se presenta formando bloques. DRAE.

52 Instrucción de Enfermeros..., pp. 140-141. 
Es importante destacar aquí que más que la eficacia de los alimentos mencionados en el tratamiento de las enfermedades contagiosas lo más importante es la toma de conciencia de la época de la necesidad imperiosa de la alimentación en la recuperación de los enfermos, la eliminación en base a la experiencia acumulada de algunos alimentos no aptos en momentos de postración y el esfuerzo denodado por mantener a los enfermos con apetencia y recuperar a los inapetentes. Todos estos alimentos mencionados en Instrucción de Enfermeros tienen un alto contenido calórico.

También se hacía especial reserva a los momentos en que los enfermos debían recibir los alimentos. Así se recoge en Instrucción de Enfermeros:

“23. Orden de dar de comer a los enfermos en las tercianas.

También tendrá cuydado el enfermero a qué hora da la calentura al paciente, para que el médico diga a qué hora se le dará de comer, porque del dar de comer cerca de las accessiones hemos visto grandes desgracias. Y assí, es muy necessario tener mucho cuydado con la hora, assí para la comida como para hazer los remedios, porque hemos visto sangrar cerca de la terciana y ser necessario darle luego los Sacramentos $[\ldots]^{\prime \prime 53}$.

Si importante se consideraba la calidad y el momento del reparto de las comidas y alimentos, también lo era todo lo relacionado con la hidratación del enfermo:

"9. Dar de beber.

Es necessario que se les dé a beber frío y más largamente que en otras calenturas y, porque en estas enfermedades suele haber desvaríos, por lo qual el enfermo no se acuerda de pedir de beber, el enfermero se lo acuerde y le dé de beber" ${ }^{24}$.

\footnotetext{
53 Ibíd. p. 148.
}

$54 \quad$ Ibíd. p. 132. 
"17. A los de dolor de costado, viruelas ${ }^{55}$ y sarampión ${ }^{56}$.

A los de dolor de costado se les ha de dar poca y, si lo pudieren llevar, con açúcar y quebrado el frío, o cozida con ciruelas passas y cebada o regaliz; y, a la declinación, con culantrillo, si fuere verano y si invierno con regaliz (como está dicho), no dándoseles fría por ningún caso.

A los de viruelas y sarampión se les ha de dar poca, porque no den en cámaras; cozida con lentejas o cebada y escorçonera, y no se les ha de dar fría con nieve porque es dañosa" ${ }^{\prime \prime 7}$.

En el siglo XVII aún seguían siendo utilizados tratamientos empleados desde la Antigüedad, como era la "piedra bezaar ${ }^{58 "}$-o "bezoar"-, más por tradición que por efectividad terapéutica ${ }^{59}$. En los casos de epidemias y grandes calamidades, sin apenas tratamientos efectivos, distintos medicamentos gozaban de especial favor entre los médicos, máxime si estos estaban reconocidos desde la Antigüedad. En Instrucción de enfermeros se enseñaba cómo debía prepararse y administrarse:

"Advertencia segunda, cómo se ha de dar la piedra bezaar.

Acostumbran los médicos en las calenturas maliciosas, viruelas y sarampión mandar echar piedra bezaar en el caldo o sustancias en aguas cordiales y

55 La viruela (del latín variola: pústula pequeña) fue una enfermedad infecciosa grave, contagiosa y con un alto riesgo de muerte, causada por el virus Variola virus El último caso de contagio natural se diagnosticó en octubre de 1977 y en 1980 la Organización Mundial de la Salud (OMS) certificó la erradicación de la enfermedad en todo el planeta. Sus principales características eran una elevada tasa de mortalidad para quienes padeciesen la enfermedad, de alrededor de un $30 \%$, con tasas especialmente elevadas en bebés y las cicatrices por todo el cuerpo, y en algunos casos ceguera, que dejaba a quienes sobrevivían.

56 El sarampión es una enfermedad muy contagiosa y grave causada por un virus. Antes de que la vacuna se introdujera en 1963 y se generalizara su uso, cada 2-3 años se registraban importantes epidemias de sarampión que llegaban a causar cerca de dos millones de muertes al año.

57 Ibíd. pp. 136-137.

58 Piedra bezaar ("piedra bezoar"). Del ár. hisp. bazáhr, este del ár. clás. b [di]zahr, y este del persa $p d z a h r^{\prime}$ defensor contra el veneno'. Concreción calculosa que suele encontrarse en las vías digestivas y en las urinarias de algunos mamíferos, y a la que se atribuyeron propiedades curativas. RAE.

59 Lindemann, Mary: Medicina y sociedad en la Europa Moderna (1500-1800). Siglo Veintiuno de España Editores, S. A. Madrid, 2001. 
darla a bever a los tales enfermos. Para darse bien, ha de ser en una cuchara de plata o de metal, si no la hubiere de palo, hinchéndola de caldo caliente o de las aguas arriba dichas y echaráse la piedra bezaar despolvoreada encima y dársela a beber si fuere possible, sin que le llegue a los dientes, y continuarle con unos tragos de caldo de las dichas aguas; ha de ser cantidad de un garbanço.

[Nota al margen]: Seys o ocho granos se suele dar de piedra de bezaar; los indios, dize Orta, que usaban della por purga, pero en más cantidad que nosotros la damos" ${ }^{\prime \prime 6}$.

En la segunda mitad del siglo XVI y todo el siglo XVII se produjo una profunda transformación de la famacopea europea, incorporándose nuevas plantas procedentes de América. Progresivamente fueron eliminándose compuestos que tradicionalmente venían siendo utilizados en los tratamientos de muchas enfermedades pero que se fueron descartando por ineficaces e, incluso, perniciosos para la salud.

\section{MEDIDAS EN BASE A LOS REMEDIOS MÉDICOS}

En este tipo de patologías infecciosas que cursaban con fiebres altas y continuas (calenturas), los médicos solían prescribir hacer sangrías, un remedio terapéutico universal que venía practicándose desde la Antigüedad, en la cual, el enfermero jugaba un papel relevante, supervisando el trabajo del sangrador o barbero: las técnicas empleadas, el instrumental y, sobre todo, anotando los síntomas posteriores mostrados por los enfermos, como se recoge en Instrucción de Enfermeros:

\section{“21. Regimiento de quando se sangran.}

Y advierta el enfermero de no dexar a los enfermos dormir, assí en los crecimientos de las calenturas continuas como quando están con las tercianas $y$, porque en estas calenturas se sangra, ha de advertir el enfermero de qué manera se ha de poner el enfermo para que le sangren, porque suelen algunos barberos sacarle el braço en alto y el cuerpo en baxo, que es uno de los mayores yerros que hasta hoy se hacen, y, assí, se ha de incorporar el enfermo y el braço un poco caydo, le sangrará.

60 Instrucción de Enfermeros..., pp. 116-117. 
Esta orden ha guardado siempre el doctor Francisco Gonçález de Sepúlueda, médico doctíssimo el qual visitó este Hospital a sus principios muchos años, cuya doctrina es muy estimada hoy en la Corte.

Y, porque en estas calenturas, por raçón de desvariar, suelen mandar echar sanguijuelas y ventosas, se hallará su doctrina en su propio lugar, capítulo 29.

$Y$, advierta el enfermero que todas las vezes que se sangraren los enfermos, avise al barbero que rompa muy bien la vena, porque de romperla poco se siguen muchos daños $\mathrm{y}$, assimismo, que si se desmayare, procure el enfermero tener agua lo más fría que pudiere y hazerle tener en quanto se sangra la boca llena della $[\ldots]^{\prime \prime 61}$.

Se consideraba de gran importancia el trabajo colaborativo entre los distintos especialistas sanitarios, médicos, cirujanos, boticarios y enfermeros.

De modo general, tanto en situaciones de epidemia y calamidad como en el día a día, el trabajo desarrollado por los enfermeros Obregones en el hospital estaba interrelacionado con el los demás profesionales, ejerciendo cada uno sus funciones y delimitándose, de esta forma, cada uno de los oficios o profesiones. Las reglas de la Congregación de los enfermeros Obregones establece todo el procedimiento en la visita diaria de los médicos a las salas del hospital y las tareas de sus hermanos:

"El modo que se tendrá en las visitas y en la execuçión de los remedios que se ordenaren a los enfermos.

A la señal que se hiçiere con la campana para la visita de los médicos y çirujanos, la cual también la tengan en lo más alto del hospital para que todos la oygan, todos los ministerios y oficios, acudirán los hermanos enfermeros de cada enfermería con sus tablas y reçeptarios.

Cada uno de los hermanos enfermeros informará y advertirá al médico de todas las yndisposiçiones que hubieren sobrebenido a cada uno de sus enfermos desde la visita pasada hasta la presente, si han dormido o no, si han hecho cámara, si ha estado ynquieto y congojado, si ha dicho algunas palabras desconzertadas, si come bien o mal, y así de otros particulares açidentes que se hoviere ofreçido para que se apliquen los remedios que para su salud convengan; y adviértase cuánto importa y conviene para la salud y vida de los enfermos, que el médico repare con atençión y asistençia en la relaçión que le hiçieren y la que los mismos enfermos le podrán dar,

$61 \quad$ Ibíd. 142-143. 
pudiendo responder a lo que el médico con blandura y despaçio los preguntare.Y esta será la más verdadera si no estuviere para responder ni dar rraçón de sí, darála con claridad y verdad su enfermero como su procurador y abogado al médico, juez de esta causa de lo que le huviere suçedido desde la visita pasada hasta la presente, teniendo consideraçión a lo que descubrieren y dijeren los testigos que son el pulso, las aguas, el subjeto, la respiraçión y semblante del enfermo" ${ }^{\prime \prime 2}$.

Los remedios para las graves enfermedades epidémicas no solían diferir en mucho de los aplicados en los hospitales para las enfermedades menos virulentas. La ciencia médica debía recorrer aún un largo camino para definir y tratar estas patologías: las sangrías, purgas, enemas y baños seguían siendo las técnicas más habituales en el quehacer diario de enfermeros y enfermos.

\section{MEDIDAS A TRAVÉS DE LOS CUIDADOS ESPIRITUALES}

"Cuidar el cuerpo y salvar el alma". No entenderemos bien la naturaleza de los hospitales de los siglos XVI y XVII si no tenemos en cuenta esta dualidad. El enfermo ingresaba en un hospital para recuperar su salud, pero esta era entendida como un todo indivisible, entre alma, cuerpo y entorno social. Por ello, las prácticas cristianas en los hospitales ocupaban un lugar central en todo el proceso de recuperación del paciente, muy especialmente cuando se preveía el final de su vida ${ }^{63}$.

Durante los meses en que la enfermedad persistiera, todo un conjunto de prácticas devocionales se sucedían. Ortiz de Zúñiga refiere que durante los años de la peste de 1649 en Sevilla se realizaron procesiones y rogativas:

"Desde el principio del contagio empezaron los clamores a Dios, poniendo por intercesora a la Reyna de los Ángeles para que su Magestad templase su ira; se hicieron rogativas en la Misa; después se continuaron con proce-

62 Obra citada: "Articulo X de las Reglas", f. 56v. Véase también García Martínez, Antonio C.; García Martínez, Manuel J.; Valle Racero, Juan I.:"Textos Históricos de Enfermería: Constituciones y Regla de la Mínima Congregación de los Hermanos Enfermeros Pobres (primera edición, año 1634)". En Híades. Revista de Historia de la Enfermería, n. ${ }^{\circ}$ 1. Alcalá de Guadaíra (Sevilla), 1994.

63 García Martínez,A. C.:"Las constituciones de los hospitales y los cuidados enfermeros en la España de los Austrias (siglos XVI-XVII). En Erebea. Revista de Humanidades y Ciencias Sociales, núm. IV (2014). Universidad de Huelva, pp. 74 y ss. 
siones a nuestra Señora de los Reyes, S. Laureano, S. Sebastián y S. Roque. Con el Lignum Crucis se hizo una por las calles, andando la plaza de San Francisco, arquillo de Chapineros, calle de Francos y, seguidamente, a la Iglesia. De noche y de secreto se hizo una ‘procesión de rogativa por las últimas naves de la Iglesia, llevando el Preste a nuestro Dios [...]"64.

"Aunque era el contagio tan fuerte, y tanta la falta de Ministros de la Santa Iglesia, no por eso se omitió la procesión del Corpus, cuyo día cayó en este año el 3 de Junio, y se hizo esta por las mismas calles que anduvo la que se había hecho con el Lignum Crucis, pero sin poder asearlas ni adornarlas $[\ldots]^{\prime \prime 65}$.

También en el interior de los hospitales, los enfermeros obregones y los capellanes de sus hospitales desarrollaban todo un conjunto de prácticas religiosas y devocionales que promovían la piedad y el recogimiento.

Todo ello pretendía transmitir esperanza y fe en Dios para que aplacara su ira y terminara con la epidemia ${ }^{66}$.

\section{Ayuda al bien morir}

Llegado el caso de los últimos momentos previos a la muerte, y máxime en situaciones de epidemias, los enfermeros Obregones procedían a ayudar al paciente a "bien morir", poniendo en marcha todo una serie de actuaciones para ello. Esta era una tarea de suma importancia llevada a cabo por la Congregación de enfermeros Obregones, insistiendo en ello ya el propio fundador, el Hermano Bernardino ${ }^{67}$.

También compusieron los enfermeros Obregones con esa finalidad y por encargo del fundador un tratado titulado Tratado de lo que se ha de hazer con los que están en el artículo de la muerte, una obra que compilaba y organizaba un conjunto de técnicas que permitían a los

64 Ortiz de Zúñiga..., p. 402.

65 Ibíd.

66 García Martínez, Manuel J.: "Ciencia y fe al servicio de la salud: los enfermeros Obregones y su contribución a la profesión enfermera en España (siglos XVI-XIX)". En Antonio Miguel Nogués y Francisco Checa (Coords.): La Cultura Sentida. Homenaje al Profesor Salvador Rodríguez Becerra. Signatura Demos. Sevilla, 2011, págs. 161-182.

67 García Martínez, Manuel J.: Cuidar el cuerpo y salvar las almas: la práctica de la Enfermería según el modelo de la Congregación de enfermeros obregones. Tesis doctoral dirigida por el prof. Salvador Rodríguez Becerra. Universidad de Sevilla, 2007. 
enfermeros ofrecer unos cuidados a los enfermos en situación terminal y que sobrellevaran mejor los últimos momentos de la vida. Esta obra solía ir acompañando al tratado de Instrucción de Enfermeros, y también conoció seis ediciones entre los siglos XVII y XVIII, una de ellas en lengua portuguesa.

Este Tratado representa, en definitiva, una guía para los enfermeros que les permitía aplicar de forma metódica su ayuda al bien morir a los enfermos durante los días en que se prolongase su agonía.

En la edición de 1728 del Tratado del bien morir, y con objeto de poner en marcha ese programa de atención a los moribundos por parte de los enfermeros, se incluyen dos interesantes capítulos dando a conocer al enfermero los principales síntomas que anuncian la muerte más o menos inmediata del enfermo, denominados:"Señales que se conocen estar los enfermos ya en estado de no poderles desamparar". En total son once señales, y también las"Señales universales de muerte", que son seis, perfectamente aplicables a los pacientes que se encuentran en fase terminal en nuestros días.

Mucha consideración prestaba Bernardino a los enfermos que estaban en el tránsito de la muerte y cuidaba que el enfermo recibiera la mayor asistencia posible en estos últimos momentos, sobre todo mandaba que no le faltase la compañía constante de algún enfermero. Para cumplir este precepto, estableció que se elaborase una relación de hermanos que debían sucederse cada hora, para que en ningún momento el enfermo agonizante quedase sin compañía:

"El enfermo que llegare al estado y última hora de su vida, aviendo rreceuido los santos Sacramentos, según está ya declarado, pondrase junto a su cama una mesilla con una toalla limpia, una lamparilla o candil encendido y una cruz, y en ella a nuestro Señor crucificado y a nuestra Señora, de bulto o de pincel, una quenta de yndulgencias, agua bendita, un libro de ayudar a bien morir, una candela de cera bendita y una canpanilla pequeña, y el Hermano Mayor escribirá en una tablilla el número de los hermanos que viere son menester para que velen una hora cada uno al dicho fatigado o fatigados ${ }^{\prime \prime 6}$.

"[...] los mismos señores no han de ocupar a nuestros hermanos en más que en la cura, regalo y limpieza de los pobres, en ayudarlos a bien morir y amonestarlos a recebir los santos Sacramentos, haziéndoselos adminis-

68 Ob. cit."Articulo X de las Reglas", f. 60r. 
tren, y enterrarlos en el cementerio del hospital y no fuera dél; y que no se meterán en el gobierno de nuestros hermanos, ni los ocuparán en oficios y cosas que contradixeren a nuestro Instituto" ${ }^{\prime \prime}$.

En tiempos de epidemia y de elevada mortandad, los cuidados de ayuda al bien morir no podrían tener la calidad y dedicación que ofrecían los enfermeros Obregones en tiempos de normalidad. Aún así, el protocolo de intervencion se intentaría aplicar en la medida de lo posible.

Las cofradías desempeñaron una importante labor asistencial en la Sevilla de los siglos XVI al XVIII, cubriendo parcelas que no lo hacían otras instituciones públicas o privadas:

"Frente a una época marcada por la práctica inexistencia de cualquier tipo de asistencia social, en comunidades marcadas por las carencias, hambrunas, enfermedades y epidemias que provocaban en conjunto fuertes sangrías humanas en su población, el fomento de la solidaridad social se reveló como uno de los principales baluartes de vertebración y organización de la sociedad como respuesta a sus necesidades de supervivencia individual y colectiva.

En este panorama de carencias vitales, y ante la presencia habitual, brutal y cotidiana de la muerte, se hicieron necesarios, pues, ciertos instrumentos de auxilios social que impulsaran una asistencia mutua dedicada al socorro en el tránsito de la vida, lo que en buena medida vino a cumplir el sistema de cofradías durante la Modernidad. Y es que la construcción cultural de la concepción de la muerte motivó la cristalización e estos principios de ayuda mutua dentro de su universo simbólico en forma de cofradías, como institutos piadosos orientados al bien morir. De este modo, y como una más de sus facetas, la utilización de la cofradía como una asociación mutual venía a llenar un espacio impreciso entre la vida y la muerte, garantizando este tránsito de un modo digno y cristiano ante la absoluta carencia de cualquier otra asistencia institucional" ${ }^{\prime 7}$.

69 Constituciones y Regla de la Mínima Congregación de los Hermanos Enfermeros pobres. Dispuestas y ordenadas por N. P. y fundador el Venerable Bernardino de Obregón, escritas de su mano y manda sus hijos las obserben y guarden. Impresa en Madrid por Francisco de Ocampo. Madrid, 1634. Cap. III.“De cómo se han de acetar los Hospitales que se nos ofrecieren", f. 60v.

70 Rodríguez Mateos, Joaquín. "Bien a los muertos y utilidad para los vivos. El auxilio funerario en las cofradías de la Modernidad". En Hernández Palomo, José J. (Coord.). Enfermedad y muerte en América y Andalucía (siglos XVI-XX). C.S.I.C. Escuela de Estudios Hispano-Americanos. Sevilla, 2004, p. 447. 
El mismo Bernardino de Obregón instituyó en Madrid una cofradía con la finalidad de dar cristiana sepultura a los enfermos pobres que fallecían en sus hospitales.

\section{CONCLUSIONES}

Tiempos actuales y tiempos pasados. Las grandes epidemias han estado presentes en la historia de la Humanidad y en cada momento se ha luchado contra ellas con los medios que los hombres tenían a su alcance.

El conocimiento en general y la ciencia médica en particular han evolucionado considerablemente con el paso de los siglos, pero las dificultades para hacer frente a las grandes epidemias siguen de plena actualidad y sin contar con los medios suficientes para superar esta importante lacra de la Humanidad.

Los enfermeros Obregones aplicaron los conocimientos de que disponían en el siglo XVII para, al menos, aliviar el dolor y el sufrimiento de los enfermos que padecieron estas terribles enfermedades; pero poco se podía hacer frente a la crudeza de las enfermedades contagiosas. El desconocimiento de estas patologías, de su diversidad, causas y mecanismos de contagio, unido a la escasez de remedios para combatirlas hacía casi imposible escapar del círculo de contagio, sufrimiento y muerte. Cuando la salvación del enfermo se veía imposible, los enfermeros Obregones dispensaban los cuidados para proporcionar una buena muerte. Poco más se podía hacer.

En pleno siglo XXI seguimos luchando contra las epidemias y de nuevo recordamos estos trágicos episodios de siglos pasados. Quizás por eso podamos comprender hoy mejor el terror que la peste ocasionaba en las gentes con tan solo pronuniciar su nombre.

Afortunadamente, en momentos tan difíciles siempre aparece lo mejor del ser humano: su entrega a los demás aún a riesgo de su propia vida. Enfermeros Obregones, hermanos de San Juan de Dios, las Hijas de la Caridad y otras congregaciones y órdenes; enfermeras y enfermeros laicos que trabajaron y lo hacen hoy en día en gran número de hospitales, grandes y pequeños, de toda España hacen posible que muchas vidas humanas se salven. 


\section{FUENTES ESCRITAS}

- "La vida del Hermano Bernardino de Obregón, Sieruo de los Pobres, Padre y fundador de los Hermanos enfermeros que los siruen en el Hospital General de Madrid y de su Congregaçión, escrita por el liçençiado Pedro de Bárçena, Comissario de la Sancta Inquisición y Arcipreste de Rauanera de Soria". Texto manuscrito incluido en el Libro Información de la uida y costumbres del Venerable Hermano Bernardino de Obregón. Anduuo en ella el Hermano Pedro Lagarto de Cepeda, natural de Toledo. Año1633. Signatura 3.466. Archivo Diocesano de Toledo.

- "Artículo X de las Reglas de la Congregación de enfermeros Obregones". Texto manuscrito incluido en el Libro 3.466 (año 1633), titulado Información de la uida y costumbres del venerable Hermano Bernardino de de Obregón. Anduuo en ella el Hermano Pedro Lagarto de Çepeda, natural de Toledo. Año1633. Archivo Diocesano de Toledo, fs. 56r-57v.

- "Pleito entre el Hermano Mayor de los Obregones del Hospital de El Arahal y los curas de la villa". Archivo General del Arzobispado de Sevilla. Signatura: "Hermandades. Arahal. Obregones". Legajo n. ${ }^{\circ}$ 218. Año 1801.

- Archivo General del Arzobispado de Sevilla (AGAS). Serie Justicia-Ordinario. Legajo n. 3.996 (signatura nueva) y 4.271(signatura antigua).

- "Libro del Protocolo del Hospital de Combalecientes titulado de Ntra. Sra. del Buen Suceso". Archivo de la Excma. Diputación Provincial de Sevilla. Hospital del Buen Suceso. Legajo 1.

- "Libro de Acuerdos desde 1677 hasta 1730. Libro de Data y Cuentas". Incluye la escritura de concordia entre la Congregación de enfermeros Obregones y la Hermandad de la Santa Caridad y Misericordia de Arahal (Sevilla). Archivo de la Santa Hermandad de la Caridad y Misericordia de Arahal.

- Basilio Beçón, G.: Tratado de la peste, y fiebre pestilente. En Zaragoca. En la Imprenta de Miguel de Luna. Impressor de la Ciudad y del Hospital Real y General de N. S. de Gracia. Ano 1655.

- Constituciones y regla de la Mínima Congregación de los Hermanos Enfermeros Pobres, Dispuestas y ordenadas por Ntro. Pre. y fundador el Venerable Bernardino de Obregón, escritas de su mano y manda sus 
hijos las observen y Guarden. En Madrid por Francisco De Ocampo. Año de 1634.

- Fernández, Andrés: Instrucción de Enfermeros para aplicar los remedios a todo género de enfermedades y acudir a muchos accidentes que sobreuienen en ausencia de los médicos. Con privilegio. En Madrid, en la Imprenta Real. Año MDCXXV.

- Tratado de lo que se ha de hazer con los que están en el artículo de la muerte. En Madrid, en la Imprenta Real. Año MDCXXV.

- López, Simón: Directorio de Enfermeros y artifice de obras de Caridad para curar las enfermedades del cuerpo. Con la pratica de sauer aplicar las Medicinas que ordenan los Medicos con el mejor arte y Methodo que ai en ella. Segun los Doctores, Anatomistas, que ensenan y senalan las partes de nuestro cuerpo donde se han de hacer. Dispuesto en ocho Tratados por Simon Lopez, Barbero de un hospital incognito. Dedicado a todos los que con Caridad desean hacer este oficio Methodicamente. IHS. Ms 259. Biblioteca Universitaria de Salamanca. Universidad de Salamanca, 1668.

- Obregón, Luis Bernardino de: Vida, y Virtudes del Siervo de Dios Bernardino de Obregon. Compuesta, por el R. P. M. Luis Bernardino de Obregon, Missionero Apostolico, Religioso Menor, en su Casa de la Ciudad de Sevilla. Sacada a luz, por el Hermano Alonso de la Santissima Trinidad, Ministro General de la Minima Congregacion de los Siervos de los Pobres Enfermos. Dedicala a la Sacratissima Virgen Maria del Buen Sucesso, como Patrona de su Congregacion, à expensas de sus Devotos. Con privilegio. En Madrid: Por Bernardo Peralta, en la Imprenta de Musica, vive en la Calle de Leganitos. Año de 1724.

- Herrera Maldonado, Francisco: Libro de la vida y marauillosas virtudes del Sieruo de Dios Bernardino de Obregon, Padre y Fundador de la Congregacion de los Enfermeros pobres y Autor de muchas obras pias de Madrid y otras partes. Con Priuilegio. En Madrid. Emprenta del Reyno. 1633.

- Collantes de Terán, Francisco: Memorias históricas de los Establecimientos de caridad. Descripción artística de los mismos. Imp. y Lit. de José M. a Ariza. Sierpes, 19. Sevilla, 1884.

- Ortiz de Zúñiga, Diego: Anales Eclesiásticos y Seculares de la muy Noble y muy Leal ciudad de Sevilla, Metrópoli de la Andalucía. Con Licencia. Madrid, en la Imprenta Real. Año de 1796. Tomo IV. Guadalquivir, S. L. Ediciones. Sevilla", 1988. 


\section{BILIOGRAFÍA}

- Betrán Moya, José L.: Historia de las epidemias en España y sus colonias (1348-1919). La Esfera de los Libros. Madrid, 2006.

- Blanco Pérez, José I.: "Luis Mercado y la traducción de textos médicos en el Renacimiento: El libro de la peste". En Ferran Grau Codina y otros (Editores). La Universitat de València $i$ l'Humanisme: Studia Humanitatis i renovaciò cultural a Europa $i$ al Nou Món. Departament de Filologia Clàssica. Universitat de València.Valencia, 2003.

- Carmona García, Juan I.: El extenso mundo de la pobreza: la otra cara de la Sevilla Imperial. Servicio de Publicaciones. Excmo. Ayuntamiento de Sevilla, 1993.

- Carmona García, Juan I.: La peste en Sevilla. Ayuntamiento de Sevilla. Área de Cultura. Sevilla, 2005.

- Carmona García, Juan I.: La Enfermedad y Sociedad en los primeros tiempos modernos. Secretariado de Publicaciones. Universidad de Sevilla. Sevilla, 2005.

- Domínguez Ortiz, Antonio: España. Tres milenios de Historia. Marcial Pons, 2000.

- García Martínez, Antonio C.: "Las Constituciones manuscritas elaboradas por Bernardino de Obregón para la Congregación de los Enfermeros Pobres (¿1592-1598?)". En Híades. Revista de Historia de la Enfermería, n. ${ }^{\circ} 10$. Alcalá de Guadaíra (Sevilla), 2008, págs. 203-254.

- García Martínez, Antonio C.: "1633, la memoria reconstruida. Estrategias de escritura y proyección social de Bernardino de Obregón en su proceso de beatificación". En María Luisa Pardo Rodríguez (Coord.). Iglesia y Escritura en Castilla. Siglos XII-XVII. Editorial Universidad de Sevilla. Sevilla, 2019, págs. 137-158.

- García Martínez, Antonio C.: "Hospitales en la España del siglo XVI, esos "otros" centros de enseñanza. Las preocupaciones de Bernardino de Obregón por la infancia". En Elena E. Rodríguez Díaz y Antonio Claret García Martínez (Eds.). Historia y Archivos. Estudios en homenaje a Dña. Remedios Rey de las Peñas. Servicio de Publicaciones Universidad de Huelva. Huelva, 2020, págs. 47-80.

- García Martínez, Manuel J.: "La hospitalización y la peste en el siglo XVII en Directorio de Enfermeros, de Simón López. Erebea. 
Revista de Humanidades y Ciencias Sociales, 4 (2014). Universidad de Huelva, 2014, págs. 119-143.

- García Martínez, Manuel J.: "Ciencia y fe al servicio de la salud: los enfermeros Obregones y su contribución a la profesión enfermera en España (siglos XVI-XIX)". En Antonio Miguel Nogués y Francisco Checa (Coords.): La Cultura Sentida. Homenaje al Profesor Salvador Rodríguez Becerra. Signatura Demos. Sevilla, 2011, págs. 161-182.

- García Martínez, Manuel J.: Cuidar el cuerpo y salvar las almas: la práctica de la Enfermería según el modelo de la Congregación de enfermeros obregones. Tesis doctoral dirigida por el prof. Salvador Rodríguez Becerra. Universidad de Sevilla, 2007.

- García Martínez, Antonio C.; García Martínez, Manuel J.: "Recuerdos de infancia de Félix Lope deVega: su testimonio en el Proceso de Beatificación del enfermero Bernardino de Obregón (año 1633)". En José María Miura Andrades y Silvia María Pérez González (Dirs.). Religiosidad sevillana. Homenaje al Profesor José Sánchez Herrero. Aconcagua Libros. Sevilla, 2012, págs. 47-78.

- García Martínez, Antonio Claret; García Martínez, Manuel Jesús: Directorio de enfermeros. Un tratado para la formación de los enfermeros en la España del siglo XVII. Consejo General de Enfermería de España. Madrid, 2017.

- García Martínez, Antonio Claret; García Martínez, Manuel Jesús: Directory for nurses. A treatise for the training of nurses in 17th century Spain. Consejo General de Enfermería de España. Madrid, 2017.

- García Martínez, Manuel J.; García Martínez, Antonio C.: "La enseñanza de la Enfermería en la España del siglo XVII. El manual de Enfermería de Simón López (1668)". En Cultura de los Cuidados. Revista de Enfermería y Humanidades. Universitat d'Alacant. Escuela Universitaria de Enfermería. CECOVA. Primer semestre de 1998. Año II, no 3, págs. 15-23.

- García Martínez, Manuel J.; García Martínez, Antonio C.: Orígenes y fundamentos de la Enfermería moderna en España. Los tratados "Instrucción de Enfermeros" y "Tratado de lo que se ha de hazer con los que están en el artículo de la muerte" (siglo XVII). Consejo General de Enfermería de España. 2. ${ }^{a}$ Edición, Madrid, 2019.

- García Martínez, Manuel J.; Valle Racero, Juan I.; García Martínez, Antonio C.: "Bernardino de Obregón, un enfermero del siglo XVI. Su papel en la reforma hospitalaria llevada a cabo por Felipe 
II. El Hospital de Convalecientes de Santa Ana". En Qalat Chábir. Revista de Humanidades, n. ${ }^{\circ}$ 1. Julio de 1993. Alcalá de Guadaíra (Sevilla), pág. 61.

- García Martínez, Antonio C.; García Martínez, Manuel J.; Valle Racero, Juan I.: Directorio de Enfermeros. Organización Colegial de Enfermería. Consejo General de Enfermería de España. Editorial Síntesis, S. A. Madrid, 1997.

- García Martínez, Antonio C.; García Martínez, Manuel J.; Valle Racero, Juan I.: "Textos Históricos de Enfermería: Constituciones y Regla de la Mínima Congregación de los Hermanos Enfermeros Pobres (primera edición, año 1634)". En Híades. Revista de Historia de la Enfermería, n. ${ }^{\circ}$ 1. Alcalá de Guadaíra (Sevilla), 1994.

- Gurpegui Resano, José R.: Alonso López de Corella. De Morbo Pustulato, sive Lenticulari, quem Nostrates Tabardillo Apellant. (Sobre la enfermedad pustulada o lenticular que los nuestros llaman Tabardillo). "Introducción, traducción y notas". Museo Vasco de Historia de la Medicina y de las Ciencias. Bilbao, 2003.

- Hernández Palomo, José J. (Coord.): Enfermedad y muerte en América y Andalucía (siglos XVI-XX). C.S.I.C. Escuela de Estudios Hispano-Americanos. Sevilla, 2004.

- Herrera, María T. (Dir.): Diccionario español de textos médicos antiguos. Editorial Arco/Libros, S. L. Madrid, 1996.

- Lindemann, Mary: Medicina y sociedad en la Europa Moderna (15001800). Siglo Veintiuno de España Editores, S. A. Madrid, 2001.

- López, Simón: Directorio de Enfermeros y Artifice de obras de caridad para curar las enfermedades del cuerpo. Estudio, transcripción e índices a cargo de Antonio Claret García Martínez y Manuel Jesús García Martínez. Biblioteca de Clásicos de la Enfermería Española, n. ${ }^{\circ}$ 1. Enfermundi. Consejo General de Enfermería de España. E-Network Salud, S. A. Sevilla, 2001.

- Martín Martín, Rafael: La Iglesia del Santo Cristo de Arahal. Historia y Arte. Hermandad del Santo Cristo de la Misericordia. Excma. Diputación Provincial de Sevilla. Sevilla, 2000.

- Sánchez, María Nieves (estudio y edición): Tratados de la peste. Arco/Libros, S. L., Madrid, 1993. 


\section{PÁGINAS WEBS}

- Real Academia Española (RAE): Diccionario de la lengua española. 23. ${ }^{a}$ edición. Octubre de 2014. On line. Disponible en: www.rae.es

- Division ofVector-Borne Infectious Diseases. National Center for Infectious Diseases. Centers for Disease Control and Prevention. Atlanta (EE. UU.).

Disponible en http://www.cdc.gov/ncidod/dvbid/dvbid.htm.

- García Martínez, Manuel J.: Cuidar el cuerpo y salvar las almas: la práctica de la Enfermería según el modelo de la Congregación de enfermeros obregones. Tesis doctoral dirigida por el prof. Salvador Rodríguez Becerra. Universidad de Sevilla, 2007. Disponible en: http://hdl.handle.net/11441/15076

- A. Blanco Quirós, Jorge M. Mata. Grupo de Trabajo de Historia y Documentación Pediátrica de la AEP: “Historia de la Medicina Vallisoletana. Luis de Mercado en el cuarto centenario de su fallecimiento (1611-2011)".

Disponible en: https://www.aeped.es/sites/default/files/luis_de_ mercado.doc. 